\title{
METHYLATION OF PHENOL OVER HIGH-SILICA BETA ZEOLITE Effect of zeolite acidity and crystal size on catalyst behaviour
}

\author{
M.Bregolato ${ }^{a}$, V.Bolis ${ }^{b}$, C.Busco ${ }^{b}$, P. Ugliengo ${ }^{c}$, S.Bordiga ${ }^{c}$, F.Cavani ${ }^{d}$, N.Ballarini ${ }^{d}$, \\ L.Maselli $^{d}$, S.Passeri ${ }^{d}$, I.Rossetti ${ }^{\mathrm{a}}$ and L.Forni ${ }^{\mathrm{a}}{ }^{\text {* }}$
}

a Dip. Chimica Fisica ed Elettrochimica, Università di Milano, via C. Golgi 19, I-20133 Milano and INSTM, Research Unit of Milano, Italy

b Dip. DiSCAFF, Università del Piemonte Orientale "A. Avogadro", Via G. Bovio 6, I-28100 Novara, INSTM, Research Unit of Piemonte Orientale and NIS Centre of Excellence, Italy ${ }^{\circ}$ Dip. Chimica IFM, Università di Torino, via P. Giuria 7, I-10125 Torino, INSTM, Research Unit of Torino and NIS Centre of Excellence, Italy

${ }^{d}$ Dip. Chimica Industriale e dei Materiali, Università di Bologna, v.le Risorgimento 4, I-40136 Bologna and INSTM, Research Unit of Bologna, Italy. A Partner of Idecat NoE, 6FP of the EU.

\section{ABSTRACT}

A systematic investigation has been carried out, aiming at elucidating several aspects of the gas/solid methylation of phenol over high Si/Al ratio BEA-structured zeolite in protonated form. The catalysts have been characterized by several techniques, such as XRD, SEM, BET, ICP, FT-IR, TGA, micro-calorimetry and modelling by ab initio calculations. The correlation between these characteristics and kinetics and mechanistic features of the catalytic reaction, as well as of catalyst deactivation, showed that these zeolites are very active for the present reaction, leading to cresols and anisole as primary products. As catalyst deactivation proceeds, the selectivity to cresols and anisole increases substantially, together with a rapid decrease of selectivity to poly-alkylated species. Catalyst surface acidity is prevalently made of medium-to-low-strength silanolsbased acid sites of Brønsted type. High-strength Lewis acid sites are either almost absent, especially when metal cations partially substitute for protons, or play a role essentially in catalyst deactivation. Stacking faults in the zeolite framework, generated by the 
intergrowth of at least two BEA polymorphs, lead to an increase of the concentration of silanols-based acid sites. Deactivation is essentially due to the interaction of phenol and oxygenated products with the strong Lewis acid sites. For time-on stream values longer than a few hours, self oligomerisation-cyclisation of methanol to olefins and aromatics, followed by further alkylation to aromatic $\mathrm{C}$ atoms, contributes more significantly to catalyst deactivation. At higher temperature all the zeolites deactivate at a comparable rate, whereas at lower temperature initial catalytic activity is higher for larger crystal size zeolite, due to the longer diffusion time of bulkier coke precursors within zeolite pores. At any conversion level and at any temperature the anisole/cresols ratio is systematically lower for the larger crystal size zeolite, since the secondary transformations of anisole to cresols, by both intra-molecular rearrangement and inter-molecular alkylation of phenol, is favoured by the longer residence time of anisole within the zeolite pores.

\section{KEYWORDS}

Methylation of phenol; Zeolite beta; Crystal size; Surface acidity; FT-IR; Microcalorimetry; $A b$ initio modelling; Catalyst activity and deactivation.

*Corresponding author: Fax +39-02-50314300, E-mail: lucio.forni@unimi.it 


\section{INTRODUCTION}

Methylation of phenol over acidic catalysts represents an industrially interesting process, by which a set of important chemicals and chemical intermediates, such as cresols, anisole and poly-alkylated phenols can be prepared [1]. The most investigated catalysts include strong Brønsted-type acid materials, such as $\mathrm{H}-\mathrm{Y}$ and $\mathrm{H}-\mathrm{ZSM} 5$ zeolites [2-13], and weaker acid catalysts as well, such as metal phosphates [14,15]. The main limit of zeolites is the low selectivity achieved to one specific compound, since several products are obtained ( $\mathrm{O}$-alkylated, mono- and poly- $\mathrm{C}$-alkylated), the selectivity of which is a function of phenol conversion, reaction conditions and zeolites characteristics. This is not the case for the heterogeneous basic-catalyzed methylation, which is a much more specific reaction. In fact, it almost exclusively yields the products of ortho- $C$-alkylation [1620].

Furthermore, alkylation reactions over solid acid catalysts, especially with reactants in gaseous phase, usually are accompanied by several unwanted side reactions, triggered by the same surface acidity of the catalyst, leading to a more or less rapid deactivation of the catalyst, due to fouling by carbonaceous deposits, usually referred to as "coke" [21]. However, it is worth noting that, to the best of our knowledge, the scientific literature on the alkylation with alcohols of phenol and of phenol derivatives, especially from the reaction kinetics point of view, does not take into consideration explicitly any catalyst deactivation effect.

The literature on gas-phase alkylation of phenol with alcohols over Beta zeolites is scarce [22-27]. Over Beta zeolite a somewhat different acidity can add to that based on $\mathrm{Al}^{3+}$ sites. Indeed, in such a zeolite randomly intergrown structures of two or even three different polymorphs, with a considerable amount of random stacking faults, leads to a substantial increase of lattice defects and structural disorder [28]. This disorder creates 
additional internal surface hydroxylated species (SiOH nests of variable geometrical arrangement) and Lewis-type (L) electron acceptor sites. As a consequence, both catalyst activity and resistance to coking are simultaneously affected by all these features, namely zeolite crystal structure and pore width, nature and concentration of surface acid sites and zeolite crystal size [29-31].

The aim of the present work was to investigate the effect on catalytic performance for phenol methylation of properly prepared samples of $\mathrm{H}$-Beta zeolite of similar Si/Al ratio, but much different crystal size. In fact, it is expected that in a complex reaction pattern, including parallel and consecutive reactions, the distribution of products can be greatly affected by the intra-particle residence time of products. Besides reaction rate and selectivity to the various products, the present analysis takes into account the activity decay and the change of selectivity with time-on-stream, looking for correlations between catalytic behaviour and the zeolites physical-chemical characteristics.

\section{EXPERIMENTAL}

\subsection{Catalyst preparation}

Three main samples of Beta zeolite, named beta-1, beta-2 e beta-3, were prepared by hydrothermal synthesis [32,33]. Tetraethyl-orthosilicate (TEOS, 98\% pure, Aldrich), tetraethylammonium hydroxide (TEAOH, 40\% aqueous solution, Fluka), sodium aluminate (56\% $\mathrm{Al}_{2} \mathrm{O}_{3}, 37 \% \mathrm{Na}_{2} \mathrm{O}$, Carlo Erba) and $\mathrm{NaOH}$ (97\% pure, Aldrich) were used as reagents. The silico-aluminate precursor gel was obtained by vigorously stirring the mixture of reagents at room temperature for several hours. After the complete hydrolysis of the organo-silicon compound, stirring was further continued for at least $24 \mathrm{~h}$ with final gentle warming, to remove the ethanol released. 
The synthesis of the zeolite was then carried out at $135^{\circ} \mathrm{C}$ (beta-1) or $150^{\circ} \mathrm{C}$ (beta-2, beta-3) in PTFE-lined stainless steel autoclaves, tumbling at 20 r.p.m. After $24 \mathrm{~h}$ for beta1, $48 \mathrm{~h}$ for beta-2 and $94 \mathrm{~h}$ for beta-3 the autoclaves were rapidly cooled and the solid was recovered from the milky suspension by centrifugation at 40,000 $\mathrm{g}$. The solid was then repeatedly washed with distilled water till neutrality of the washing liquid, dried at $120^{\circ} \mathrm{C}$ overnight and calcined in nitrogen and air flow up to $550^{\circ} \mathrm{C}$, to remove the $\mathrm{TEAOH}$ trapped in the channels of the zeolite crystals. The as-prepared samples were then ion-exchanged three times for three hours at $80^{\circ} \mathrm{C}$ with fresh $0.1 \mathrm{M}$ ammonium nitrate (Janssen, "pro analysi") solution. After the final exchange, the solid was separated by centrifugation, repeatedly washed with distilled water and calcined in air at $550^{\circ} \mathrm{C}$, to obtain the final protonated zeolite by decomposition of the ammonium ion.

A fourth sample (beta-silicalite, with $\mathrm{Si} / \mathrm{Al}$ ratio $>500$ ) was also prepared for characterisation comparison purposes only. This required the preparation of the special templating agent 4,4'-trimethylene-bis(N-benzyl, $\mathrm{N}$-methyl-piperidinium)-dihydroxide, the usually employed TEAOH failing in leading to the desired BEA structure for very high Si/AI ratios [34].

Beta-10 was a sample kindly supplied by Polimeri Europa srl and it has been used for comparative characterisation purposes only.

The template solution was prepared as follows: $77 \mathrm{~g}$ of 4,4'-trimethylene-bis-(1-methylpiperidine) (Aldrich, $98+\%$ pure) were dissolved in $103 \mathrm{~g}$ of ethanol (Fluka, anhydrous). To this solution $110 \mathrm{~g}$ of benzyl bromide (Fluka, 98\% pure) were added dropwise under vigorous stirring. The solid dibromide precipitate so formed was repeatedly washed with anhydrous ethanol and dried under flowing nitrogen. The dihydroxide was then obtained from the dibromide by electro-dialysis, by employing an electrolytic cell equipped with an anionic membrane separating the cathodic $0.46 \mathrm{M}$ bromide solution from the anodic 25 
wt\% aqueous ammonia solution. The final $0.79 \mathrm{M}$ solution of the templating agent was finally obtained by low-temperature removal of excess water.

The synthesis of beta-silicalite was then carried out as previously described, in the absence of sodium aluminate and by substituting the 4,4'-trimethylene-bis( $\mathrm{N}$-benzyl,Nmethyl-piperidinium)-dihydroxide for TEAOH.

\subsection{Catalyst characterisation}

Identification of crystalline structure was accomplished by X-ray diffraction (XRD), by means of a Philips PW 1820 powder diffractometer, operated at $40 \mathrm{kV}$ and $40 \mathrm{~mA}$, with Nifiltered, Cu-Ka radiation $(\lambda=1.5418 \AA)$. The BET specific surface area (SSA) was measured by $\mathrm{N}_{2}$ adsorption-desorption at liquid nitrogen temperature, on a Micromeritics ASAP 2010 instrument. Zeolite crystal size and shape were determined by scanning electron microscopy (SEM), by either a Cambridge Stereoscan 150 or a Leica LEO 1430 instrument. Elemental analysis was performed on a Varian Liberty 200 inductively coupled plasma (ICP) spectrometer.

Catalyst surface acidity was measured by FT-IR spectroscopy, by means of a PerkinElmer 1750 Spectrometer. Self-supporting wafers of pure zeolite were first evacuated at $500^{\circ} \mathrm{C}$ in vacuo (residual $\mathrm{p}=10^{-6} \mathrm{mbar}$ ). Then adsorption of pyridine was done at room temperature, and desorption was carried out by outgassing the sample at 50, 150, 250, $350,450^{\circ} \mathrm{C}$. The FT-IR spectrum was recorded after evacuation at each temperature level.

The reactivity towards $\mathrm{CH}_{3} \mathrm{OH}$, the large-excess reactant of the methylation reaction (vide infra), has been investigated also by IR spectroscopy. The interaction between $\mathrm{CH}_{3} \mathrm{OH}$ and beta-1, beta-2 and beta-3 catalysts, after pre-activation in vacuo (residual $\mathrm{p}=$ $10^{-5}$ Torr) at $773 \mathrm{~K}$, has been analysed at $2 \mathrm{~cm}^{-1}$ resolution on a Bruker IFS 66 FT-IR spectrometer, equipped with MCT detector. The samples were pre-evacuated as for the acidity measures (vide supra). 
The adsorption features of the catalysts have been investigated by contacting (at 303 K) the activated samples with $\mathrm{CH}_{3} \mathrm{OH}$ vapour, as well as with $\mathrm{H}_{2} \mathrm{O}$ vapour, in order to investigate the hydrophilic/hydrophobic properties of the catalysts. The study was performed by using a heat-flow micro-calorimeter Tian-Calvet type (C80 by Sétaram) connected to a high-vacuum gas-volumetric glass apparatus, equipped with a Ceramicell 0-100 Torr transducer gauge by Varian, following a well established procedure [35-37]. All samples were activated in vacuo for $2 \mathrm{~h}$ at a residual pressure $\mathrm{p} \leq 10^{-5}$ Torr at $\mathrm{T}=873 \mathrm{~K}$ for $\mathrm{H}-\mathrm{BEA}$, and at $\mathrm{T}=673 \mathrm{~K}$ for the all-silica zeolite. The individual activation temperature was selected according to the indications of IR spectroscopy (spectra not reported for brevity), so to achieve the maximum dehydration of the surface compatible with the stability of the structure and aiming at the maximum density of Lewis and Brønsted acidic sites. $\mathrm{CH}_{3} \mathrm{OH}$ and $\mathrm{H}_{2} \mathrm{O}$ were distilled in vacuo and outgassed by several freeze-pump-thaw cycles. The adsorption measurements have been performed at least twice on a virgin portion of the same batch of the materials, activated under the same conditions, in order to check the reproducibility of the experiments.

At last, a calculation was made relative to the interaction of $\mathrm{CH}_{3} \mathrm{OH}$ and $\mathrm{H}_{2} \mathrm{O}$ molecules with a molecular cluster simulating a coordinatively unsaturated framework $\mathrm{Al}(\mathrm{III})$ site acting as Lewis (L) acidic site. All calculations have been run at ab-initio level using the B3-LYP/6-31+G(d,p) model chemistry [38]. The binding energies (BE) of the probe molecules with the $L$ site have been calculated, and compared to the enthalpy change associated to the adsorption processes on the real systems.

\subsection{Catalytic activity tests}

Methylation of phenol was carried out in a continuous down-flow tubular reactor, at four different temperatures, ranging from 320 to $450^{\circ} \mathrm{C}$, at atmospheric total pressure. An excess of methanol with respect to the stoichiometric requirement for the methylation of 
phenol was fed (methanol/phenol feed ratio $=7 / 1$ ). In fact, due to the strong interaction between phenol and the catalyst, acceptable reaction rates are obtained only when the partial pressure of methanol is much higher than that of phenol. Usually methanol/phenol feeding ratios higher than 5 are used [39] for an analysis of the effect of such a ratio on catalytic performance, so to obtain a phenol conversion higher than $10-20 \%$ at $\mathrm{T}<400^{\circ} \mathrm{C}$. On the other hand, feeding ratios higher than 10 favour the formation of poly-alkylated phenols. Our aim was to investigate the selectivity ratio between $O$ - and $C$-alkylated compounds, with minimal formation of poly-alkylated products. Therefore, a methanol/phenol molar ratio of $7 / 1$ was selected as a compromise between these two counteracting effects.

$0.6 \mathrm{~g}$ of catalyst were loaded. The flow rate of reactants was $60 \mathrm{~cm}^{3} / \mathrm{min}$ of gaseous $\mathrm{N}_{2}$ and $1.75 \times 10^{-3} \mathrm{~cm}^{3} / \mathrm{min}$ of organic liquid feeding mixture, so to have a value of residence time $\tau=0.98 \mathrm{~s}\left(\mathrm{~cm}^{3}\right.$ catalyst bed $\mathrm{S} / \mathrm{cm}^{3}$ overall gaseous feeding flow $)$. The reactor temperature was kept to the desired value by an electric furnace surrounding the reactor and governed by a TRC, through a thermocouple placed within the catalyst bed. Reactor effluent analysis was made by means of a Thermo, Focus GC gas chromatograph, equipped with a HP-5 semicapillary column.

When needed, the catalyst was regenerated in situ in flowing air $\left(20 \mathrm{~cm}^{3} / \mathrm{min}\right)$ by increasing temperature by $5^{\circ} \mathrm{C} / \mathrm{min}$ from room temperature up to $300^{\circ} \mathrm{C}$, then by $0.83^{\circ} \mathrm{C} / \mathrm{min}$ up to $350^{\circ} \mathrm{C}, 400^{\circ} \mathrm{C}$ and $450^{\circ} \mathrm{C}$. After each temperature step (i.e. at 300. 350 , 400 and $450^{\circ} \mathrm{C}$ ) temperature was kept constant for $1 \mathrm{~h}$.

\subsection{Coke analysis}

Samples of aged catalyst, recovered after a few hours on-stream at $390^{\circ} \mathrm{C}$, were analysed according to a well-known technique [40], to collect information on the amount and nature of the fouling carbonaceous material (coke). A weighed portion of aged catalyst 
was disaggregated in $\mathrm{HF}(40 \%$ aqueous solution) to dissolve the zeolite and to collect the remaining carbonaceous solid particles by filtration and drying. The carbonaceous solid particles were repeatedly leached with small portions of fresh $\mathrm{CH}_{2} \mathrm{Cl}_{2}$ and then dried and weighed. The leaching $\mathrm{CH}_{2} \mathrm{Cl}_{2}$ solutions were combined and most of the solvent removed in vacuo at room temperature. The concentrated solution of the soluble coke was then analysed by gas chromatography-quadrupolar mass spectrometry (GC-QMS) by an Agilent HP 5973N GC-MS instrument.

Furthermore, on beta-1 and beta-2 aged samples only, the amount of accumulated carbonaceous matter was evaluated also by thermogravimetry in air on a TA TGA 2050 Instrument. The following heating program was followed: $80^{\circ} \mathrm{C}$ in flowing $\mathrm{N}_{2}$ for $5 \mathrm{~min}$, heating from $80^{\circ} \mathrm{C}$ to $550^{\circ} \mathrm{C}\left(5^{\circ} / \mathrm{min}\right)$ in $60 \mathrm{ml} / \mathrm{min}$ flowing air and final isothermal step at $550^{\circ} \mathrm{C}$ for $60 \mathrm{~min}$.

\section{RESULTS AND DISCUSSION}

\subsection{Catalysts characterisation}

\subsubsection{Crystal phase, surface area, crystal size and $\mathrm{Si} / \mathrm{Al}$ ratio}

Under the synthesis conditions adopted, BEA zeolite was the only crystalline phase obtained. The XRD patterns matched those reported in literature [41-43]. Our BEA samples (Fig.1) were the result of intergrowth of two polymorphs, A and B [43], or even of a third polymorph C [42]. However, our XRD patterns did not allow any reliable quantitative determination of the polymorph distribution.

SSA ranged from 480 to $570 \mathrm{~m}^{2} / \mathrm{g}$ (Table 1), typical values for these zeolites. SEM micrographs (Fig.2a,b,d) showed that beta-1, beta-2 and beta-silicalite were composed of spheroidal-shaped crystals with a narrow crystal size distribution. The beta-3 crystals 
appeared slightly cuboidal-shaped (Fig.2c). The average size of particles, determined by direct measurement on properly enlarged micrographs for the various zeolites, is given in Table 1. Total pore volume ( $\left.V_{\text {ртоT}}\right)$ and micropore volume ( $V_{\text {pMicr }}$ (Table 1), determined from the total gas volume adsorbed at saturation and t-plot data, may give an idea of the crystallinity of our samples.

ICP analysis showed for all samples a similar $\mathrm{SiO}_{2} / \mathrm{Al}_{2} \mathrm{O}_{3}$ molar ratio (Table 1), except of course for the beta-silicalite. Furthermore, the protonated beta-2 and beta-3 (and mainly beta-silicalite) catalysts were almost $\mathrm{Na}$-free, whereas the beta-1 sample contained a considerable amount of exchangeable $\mathrm{Na}^{+}$ions (Table 1).

\subsubsection{Reactivity toward $\mathrm{CH}_{3} \mathrm{OH}$ from FTIR spectroscopy}

All the beta samples are characterized by a very low Al content (Table 1). This, accompanied by the high structural defectivity (vide supra) of these zeolites, which is associated with a large abundance of silanols, becomes relevant in the spectroscopic features of their reactivity with $\mathrm{CH}_{3} \mathrm{OH}$. Another important point is the concentration of residual $\mathrm{Na}^{+}$species, rather abundant $(2.42 \mathrm{wt} \%$, Table 1$)$ in beta-1 sample only.

After activation at $773 \mathrm{~K}$ all samples (Fig.3a) did not present IR bands over $3750 \mathrm{~cm}^{-1}$, characteristic of the hydroxyl groups bound to extra-framework Al (EFA) and all samples showed a strong maximum at $3740 \mathrm{~cm}^{-1}$, due to nearly isolated silanols. Another common characteristic is the broad tail at lower frequency, extending till $3400 \mathrm{~cm}^{-1}$, indicating the presence of an abundant fraction of interacting hydroxyls. No further specific absorption are evident in beta-1 sample: in particular no bands are recognized in the region where bridging $\mathrm{OH}$ groups are expected. This observation is in agreement with the fact that beta1 sample has mainly $\mathrm{Na}^{+}$as counterions. Beta- 2 sample was characterised by a broad tailed signal, extending from 3740 to $3400 \mathrm{~cm}^{-1}$, due to $\mathrm{H}$-bound silanols. A second weak maximum is observed at $3580 \mathrm{~cm}^{-1}$, where the band due to bridged $B$ groups $\left(3615 \mathrm{~cm}^{-1}\right)$ 
is superimposed. The situation is very similar to that observed in beta-3 sample, that shows an even more complex shape of the band in the $\mathrm{OH}$ stretching region: peak at 3613 $\mathrm{cm}^{-1}$ superimposed to the broad component due to $\mathrm{H}$-bonded silanols (maximum at 3500 $\left.\mathrm{cm}^{-1}\right)$. Also in this case an evaluation of the concentration of bridged B groups is prevented by the mixing with the silanols components.

Figure $3 b$ shows the reactivity towards $\mathrm{CH}_{3} \mathrm{OH}$ of beta 2 and 3 . The data on the Na-rich sample, beta-1, are not reported because they did not show any feature associable with bridging Brønsted acid sites. In particular, after interaction with methanol no specific signals ascribable to strong acid sites was noticed (total absence of $A, B$ and $C$ signals, vide infra). In addition, a considerable reversibility of the interaction of beta-1 with methanol was observed, a behaviour typical of purely siliceous materials. This is very likely due to the saturation by $\mathrm{Na}^{+}$ions of the strongest acid sites generated by the framework $\mathrm{Al}$ ions.

As demonstrated by Pazè et al. [44], in the presence of molecules like $\mathrm{H}_{2} \mathrm{O}$ or $\mathrm{CH}_{3} \mathrm{OH}$ with medium to high proton affinity, a zeolite, which is characterized by the presence of high Brønsted acidity, is able to realize a strong $\mathrm{H}$-bond interaction, which produces two main effects: at first the band associated to the $\mathrm{OH}$ stretching mode is strongly red-shifted, generating an intense and broad absorption which can be extended until $1000 \mathrm{~cm}^{-1}$, while the band due to the overtone of the bending mode of the same species is deeply blueshifted. From a theoretical point of view, the phenomenon is called Fermi Resonance and the effect on the spectra is the appearance of three bands identified as $A, B$ and $C$, separated by two Evan's windows: the presence and the relative intensity of these three bands indicate the entity of the interaction and consequently the acidity of the material [4448].

Coming to the effect of increasing dosages of methanol on beta-2 sample (upper left of Fig.3b), one may observe the progressive erosion of the $\mathrm{OH}$ bands and the growth of a 
very broad absorption with a maximum centred at about $3400 \mathrm{~cm}^{-1}$. This absorption extends till the region of framework vibration, suggesting the presence of some species strongly engaged by methanol. However, as these species are only a minor feature with respect to silanols (characterised by a medium-low-strength acidity) we do not observe clearly, the formation of the A, B, C components. Around $3000 \mathrm{~cm}^{-1}$, the $\mathrm{C}-\mathrm{H}$ stretching vibrations of $\mathrm{CH}_{3} \mathrm{OH}$ are superimposed. In particular, the absorptions at 3000 and 2958 $\mathrm{cm}^{-1}$ represent asymmetric vibrations, whereas that at $2854 \mathrm{~cm}^{-1}$ is associated with symmetric modes of the $\mathrm{CH}_{3}$ groups. The frequencies are slightly shifted upward, compared to the vibrations of the free molecule. The band at $2916 \mathrm{~cm}^{-1}$ is probably due to overtones of the $v\left(\mathrm{CH}_{3}\right)$ bending mode at $1450 \mathrm{~cm}^{-1}$, enhanced by a Fermi resonance effect [49].

The interaction with methanol was not completely reversible on beta-2, as evidenced by the lower-left of Fig.3b. In particular, only part of the external silanols are restored, while the majority of the $\mathrm{OH}$ groups are unaffected by prolonged outgassing at room temperature. The fact that methanol is still entrapped within the zeolite cavities is evidenced also by the permanence of the bands associated with the $\mathrm{C}-\mathrm{H}$ vibration modes around $3000 \mathrm{~cm}^{-1}$.

Coming to the data related to the beta-3 sample (upper right of Fig.3b), at low methanol loading we can distinguish the A, B, C triad, caused by Fermi resonance of the $v$ stretching and $2 \delta$ and $2 \gamma$ overtones of bond 1 (Scheme 1 ).

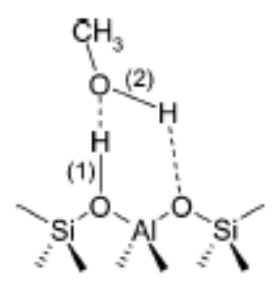

Scheme 1

This in turn induces the formation of two Evans windows, one at about $2720 \mathrm{~cm}^{-1}$ and the other at $2000 \mathrm{~cm}^{-1}$. The approximate frequency of the $v(\mathrm{OH})$ mode of (zeolite- 
$\mathrm{H} . . . O_{\text {methanol }} 1$ in the absence of Fermi resonance effects can be estimated to $2100 \mathrm{~cm}^{-1}$. The corresponding vibration mode of bond 2 (see Scheme 1) is assigned to a component growing at $3500 \mathrm{~cm}^{-1}$. This band grows in parallel with the A, B, C triplet and confirms the formation of a neutral adduct. The evolution of the spectra in the $2000-1300 \mathrm{~cm}^{-1}$ range, where the C component is growing, shows a higher level of complexity. Negative components originate from perturbative effects on the zeolitic framework, inferred by $\mathrm{CH}_{3} \mathrm{OH}$. Moreover, an additional negative band, growing at $1450 \mathrm{~cm}-1$, corresponds to an Evans window, because of the superposition of the $\mathrm{C}$ component with $\delta\left(\mathrm{CH}_{3}\right)$ mode.

At high methanol coverage the spectra are dominated by an unstructured broad band extending over the entire medium IR region, overshadowing the $A, B, C$ components associated to the formation of the methanol-silanol adducts.

Also with beta-3 the interaction with methanol is only partially reversible, as evidenced by the effect of prolonged outgassing at room temperature (lower right of Fig.3b). The last collected spectrum (bold curve) is very similar to what obtained with the beta-2 sample.

It may be concluded that the present materials possess a low concentration of structural $\left(\mathrm{SiOH}^{-} \mathrm{Al}^{+}\right)$strong Brønsted acid sites, most of the surface acidity consisting of relatively weaker ( $\mathrm{SiOH}$ nests) Brønsted silanol species. At reaction temperature the slightly higher abundance of strong acidic sites present in beta-3 sample could play only a minor effect on overall catalytic activity. This acidity distribution can be considered one of the major causes of the relatively lower deactivation rate of high-silica BEA zeolite.

Table 2 gives a summary of the most important IR spectroscopic features of the present samples.

\subsubsection{Energetics and hydrophilicity/hydrophobicity of active sites}

Energetics of adsorption and hydrophilic/hydrophobic properties of the present catalysts have been investigated, as mentioned, by progressive adsorption of $\mathrm{CH}_{3} \mathrm{OH}$ and 
water vapour, monitored by micro-calorimetry. Integral heat evolved $\left(Q^{\text {int }}\right)$, as well as adsorbed amount ( $\mathrm{n}_{\text {ads }}$ ) for small adsorptive increments, were determined in the same experiment, following the previously mentioned procedure [35-37]. The reversibility/irreversibility upon room temperature evacuation of first-run-adsorbed phase (ads. I) was checked by performing a second adsorption run (ads. II) after outgassing the sample overnight (residual $\mathrm{p} \leq 10^{-5}$ Torr). The adsorbed amounts $\left(\mathrm{n}_{\text {ads }}=\mathrm{CH}_{3} \mathrm{OH}\right.$ or $\mathrm{H}_{2} \mathrm{O}$ molecules per unit cell) were collected as volumetric isotherms. Calorimetric data were collected either as differential heats of adsorption ( $q^{\text {diff }}=\delta Q^{\text {int }} / \delta n_{\text {ads }}$ ), or as integral molar heats of adsorption $\left[q^{\text {mol }}\right]_{p}=\left(Q^{\text {int }} / n_{\text {ads }}\right)_{p}$. The $\left[q^{\text {mol }}\right]_{p}$ quantities are intrinsically average values, as they refer to the thermal response of the surface as a whole, from the beginning of the adsorption process up to the equilibrium pressure, whereas the $q^{\text {diff }}$ quantities represent a reasonable measure of the energy of interaction of the probe molecule with the individual sites, at any adsorbate coverage.

The results for beta- 2 and beta-3 samples with $\mathrm{CH}_{3} \mathrm{OH}$ as probe are shown in Fig.4. The $\mathrm{q}^{\text {diff }} v s . \mathrm{n}_{\text {ads }}$ plots give a detailed description of the surface heterogeneity. In particular, the differential heat of adsorption, extrapolated to vanishing coverage ( $q_{0}, \mathrm{~kJ} / \mathrm{mol}$, Table 1 ), represents the enthalpy change associated with the adsorption on the most energetic sites. Values of the same order of magnitude have been obtained for the binding energy $(\mathrm{BE}, \mathrm{kJ} / \mathrm{mol}$ ) through the ab initio calculations (vide infra) for the individual molecular probe interaction with the model Lewis acid site and corrected for the basis set superposition error by the standard Boys-Bernardi counterpoise method [50].

By inspecting Fig.4 one may observe that: $l)$ The $q^{\text {diff }} v s . \mathrm{n}_{\text {ads }}$ experimental points of both beta- 2 and beta- 3 zeolites are best fitted by the same curve, indicating that no significant difference in the acid strength of the two catalysts can be evidenced by means the room-temperature adsorption of $\mathrm{CH}_{3} \mathrm{OH}$. The curve starts at $\mathrm{q}_{0} \sim 130 \mathrm{~kJ} / \mathrm{mol}$ and drops down quite smoothly, eventually approaching the latent heat of liquefaction of $\mathrm{CH}_{3} \mathrm{OH}$ (38 
$\mathrm{kJ} / \mathrm{mol}$ ) at a coverage corresponding to ca.12 molecules adsorbed per unit cell. ii) The only detectable differences between the two catalysts is that the $\mathrm{CH}_{3} \mathrm{OH}$ adsorption capacity is significantly larger for beta-3 (see inset of Fig.4), the number of molecules adsorbed per unit cell at any equilibrium pressure investigated being higher than for beta-2. We ascribe this difference to the different Si/Al ratio, being the Al content of beta-3 slightly higher than for beta-2, though the two values of Si/Al ratio are too close (130 for the former against 154 for the latter, Table 1) to permit a more detailed comparison. iii) The irreversibly adsorbed $\mathrm{CH}_{3} \mathrm{OH}$, evaluated by the difference between the ads. I and ads. II curves, the latter drawn after outgassing overnight the reversibly adsorbed alcohol of ads. I, amounted to ca. $20 \%$ of the total amount adsorbed by both zeolites. Still, the $q^{\text {diff }} v s$. $n_{\text {ads }}$ experimental points for the $2^{\text {nd }}$ run were best fitted by the same curve, indicating that neither for reversible adsorption a significant difference between the two catalysts is evidenced by using $\mathrm{CH}_{3} \mathrm{OH}$ as molecular probe. iv) The quantitative calorimetric data are in agreement with the data from the IR analysis (vide supra).

As a preliminary conclusion, beta-2 and beta-3 catalysts show a distribution of acid sites of comparable strength, which abundance is in line (as expected) with Al content, though some effect of materials morphology, and especially of zeolite crystal size, cannot be excluded.

The differential heat of adsorption of $\mathrm{H}_{2} \mathrm{O}$ vapour is reported (Fig.5) as a function of the increasing surface coverage ( $q^{\text {diff }} v s$. $n_{a d s}$ ) for all the catalysts investigated in the present work. For comparison purposes a Al-free beta-silicalite has been added, together with a previously investigated $[35,51]$ beta-10 sample, characterized by a much higher Al content $(\mathrm{Si} / \mathrm{Al} \approx 10)$ i.e. by a much higher number of $\mathrm{Al}$ atoms per unit cell $(\sim 6$, Table 1$)$. The corresponding volumetric isotherms are shown in the inset. For brevity, in both $\mathrm{q}^{\text {diff }} v s$. nads and $n_{\text {ads }} v s$. peq plots only the first-run adsorption data are reported and discussed, but it has been found that in all catalysts (irrespective of the Al content) a fraction of water 
molecules was irreversibly adsorbed, whereas for the beta-silicalite the adsorption was found entirely reversible upon room-temperature outgassing. One may observe that: i) Initially the experimental data of $\mathrm{q}^{\text {diff }} v s$. coverage for beta-2 and beta-3 are best fitted by the same curve as for the $\mathrm{CH}_{3} \mathrm{OH}$ q diff $v$ s. $\mathrm{n}_{\text {ads }}$ plots (Fig.4), partially confirming the close similarity of the acidic and hydrophilic properties of the two systems. However, the curve starts at $q_{0}=160 \mathrm{~kJ} / \mathrm{mol}$ for the two samples, but drops more rapidly for beta-3 than for beta-2, eventually approaching the latent heat of liquefaction of water $(\mathrm{q} L=44 \mathrm{~kJ} / \mathrm{mol})$ at a much lower coverage for beta-3 than for beta-2. Indeed, opposite to methanol, the beta-3 $\mathrm{H}_{2} \mathrm{O}$ adsorption capacity is much lower than for beta-2 (see the volumetric isotherms in the inset), indicating that, though the Al content of beta-3 is slightly higher than for beta- 2 , the population of sites active towards $\mathrm{H}_{2} \mathrm{O}$ of the former is lower than that of the latter. In conclusion, the beta-3 zeolite is less hydrophilic than beta-2, in spite of the lower Si/Al ratio, as if the larger crystal size of the former would inhibit the interaction with water. in) The qo value (close to $100 \mathrm{~kJ} / \mathrm{mol}$ ) for the Na-rich beta-1 catalyst is much lower than for beta- 2 and beta- 3 , as expected. Furthermore, as far as the coverage increases, the beta- 1 curve does merge into the beta-2 curve, according to the closer similarity of the crystal size. It is worth noting that the beta-1 water adsorption capacity (per unit cell) is only slightly lower than for beta-2, and much higher than for beta-3, according to the lower concentration of strong acid sites (see inset of Fig.5). iii) The quiff $v s . n_{\text {ads }}$ plot for betasilicalite lies below those of the other catalysts in the whole examined range of coverage, in agreement with the absence of strong acidic sites, associated with framework Al species. The $\mathrm{q}_{0}$ value for this sample is close to $80 \mathrm{~kJ} / \mathrm{mol}$, much lower than for other zeolites. It is however worth noticing that the $\mathrm{q}^{\text {diff }} v s$. $\mathrm{n}_{\text {ads }}$ plot for beta-silicalite lies above the latent heat of liquefaction of water $\left(\mathrm{q}_{\mathrm{L}}=44 \mathrm{~kJ} / \mathrm{mol}\right)$, as typical of an hydrophilic surface [35-37]. 
By comparing the results obtained for the present-work beta zeolites with those previously obtained by some of us on beta- 10 , the difference in calorimetric response of the Al-rich beta- 10 system is dramatically evident, in that both beta- 10 qdiff $v s . n_{\text {ads }}$ and $n_{\text {ads }}$ vs. peq plots lie well above the corresponding curves for the present-work beta zeolites. This strongly confirms that the population of strong acidic sites is much more abundant in the beta- 10 catalyst, as expected. However, the very initial heat of adsorption of water is quite close for beta-2, beta-3 and beta-10 catalysts ( $q_{0} \sim 160 \mathrm{~kJ} / \mathrm{mol}$ in all cases), suggesting that the difference in calorimetric response is connected to the abundance, more than to the strength of acid sites.

The integral molar heat of adsorption $\mathrm{q}_{\mathrm{mol}}$ (vide supra) determined at equilibrium pressure corresponding to either 2 or $4 \mathrm{H}_{2} \mathrm{O}$ molecules/uc coverage are shown in Fig.6 a and $b$, respectively, as a function of the crystal size of the investigated materials (see Table 1). Again the beta-10 datum is reported for comparison. It can be noticed that: $l$ The qmol value is very close $(\sim 85 \mathrm{~kJ} / \mathrm{mol}$, irrespective of the crystal size $)$, for all the present catalysts, characterized by a close Si/Al ratio $(130<\mathrm{Si} / \mathrm{Al}<154)$. il) The $\mathrm{q}_{\mathrm{mol}}$ value for beta-silicalite is lower $(\sim 50 \mathrm{~kJ} / \mathrm{mol})$, according to the fact that in this case only $\mathrm{H}$-bonding interactions, much less energetic than both the Lewis and Brønsted acid-base interactions, are operative. iii) The $\mathrm{q}_{\mathrm{mol}}$ value for beta-10 is much higher $(\sim 160 \mathrm{~kJ} / \mathrm{mol})$, since a coverage of $2 \mathrm{H}_{2} \mathrm{O}$ molecules/unit cell is still very low (only one third of acidic sites associated to framework $\mathrm{Al}$ have already reacted). iv) At $4 \mathrm{H}_{2} \mathrm{O}$ molecules/unit cell coverage, over beta-10 a few strong acidic sites remain still available, but in this case the $q_{\text {mol }}$ values (which are intrinsically average values, including all interactions contributions) are much closer $(\sim 100 \mathrm{~kJ} / \mathrm{mol})$ to the $\mathrm{q}_{\mathrm{mol}}$ values $(\sim 75 \mathrm{~kJ} / \mathrm{mol})$ for the beta-1-2-3 catalysts. v) At high coverage the difference between the beta-1-2-3 set and beta-silicalite is much smaller, according to the fact that at such a coverage also in the beta-1-2-3 catalysts the 
interaction is dominated by $\mathrm{H}$-bonding (on both silanols and already adsorbed water molecules).

Fig.7 shows the B3LYP/6-31+G(d,p) optimized structures of the clusters adopted to mimic the $\mathrm{L}$ acid site interacting with the $\mathrm{CH}_{3} \mathrm{OH}$ (a) and $\mathrm{H}_{2} \mathrm{O}$ (b) molecule. The calculated binding energies $(\mathrm{BE})$ are 125 and $110 \mathrm{~kJ} / \mathrm{mol}$, respectively. These values are in agreement with the calorimetric energetic data (differential heats of adsorption) measured in the early stage of the process and suggest that at least a fraction of acid sites is likely Lewis in nature.

\subsubsection{Nature and strength of surface acid sites}

Fig.s 8 and 9 show the FT-IR spectra recorded after pyridine adsorption at room temperature, followed by desorption at increasing temperatures, for samples beta- 1 and beta-2, respectively. In the case of beta-1 (Fig.8) the intensity of the band associated to pyridinium cation (1546 $\mathrm{cm}^{-1}$ ) is nil, that relative to the interaction with Lewis sites (1455 $\mathrm{cm}^{-1}$ ) is very weak, and pyridine is totally released already after evacuation at $250^{\circ} \mathrm{C}$. Finally, the amount of pyridine interacting with silanols (bands at 1446 and $1596 \mathrm{~cm}^{-1}$ ) [52] is lower than in beta-2 catalysts (Fig.9). In beta-1, silanols are clearly the only sites present in non-negligible amount.

In the case of beta-2 (Fig.9), the strong bands at 1446 and $1596 \mathrm{~cm}^{-1}$, due to pyridine adsorbed on silanols, progressively decrease when increasing temperature and totally disappear after evacuation at $250^{\circ} \mathrm{C}$. By contrast, some pyridine adsorbed on Lewis sites $\left(1455 \mathrm{~cm}^{-1}\right)$ remains even after evacuation at $450^{\circ} \mathrm{C}$. This indicates the presence of strong Lewis-type acid sites, in line with what found by the other techniques. The band at $1546 \mathrm{~cm}^{-1}$, due to the interaction with Brønsted sites, is very weak, as expected from the low concentration of these sites in high-silica zeolites. When the sample is heated, the intensity first increases, likely due to the evolution of the hydrogen bonding with the $-\mathrm{OH}$ 
group into pyridinium ions, and then decreases; totally disappearing after evacuation at $450^{\circ} \mathrm{C}$. The spectra recorded with beta-3 samples (not reported for brevity) were very similar to those of beta-2.

\subsection{Catalyst activity and deactivation rate}

There is a wide literature dealing with the use of zeolites as catalysts for the liquidphase and gas-phase methylation of phenol. With MFI zeolites, at temperature higher than $350^{\circ} \mathrm{C}$ Kaliaguine et al. [2,53] found that the reaction leads to a variety of products, amongst which the most relevant were cresols and xylenols. A mechanism was proposed in which diphenyl ether and anisole (the two products of etherification) are the reaction intermediates and interact with Brønsted sites and carbonium ions to yield $C$-methylated products. The reaction pattern was confirmed by others [12], who also found that in liquidphase methylation anisole and cresols are primary products and that anisole undergoes consecutive transformation to cresols.

With $\mathrm{H}-\mathrm{Y}$ zeolites, at $200^{\circ} \mathrm{C}$ and phenol conversion lower than $15 \%$ O-alkylation was found to be quicker than $C$-alkylation (the two reactions were substantially parallel), with oIp-cresol molar ratio equal to 1.5. Anisole disproportioned into phenol and methyl-anisoles, whereas direct isomerisation of anisole into cresols did not occur. Anisole also acted as an alkylating agent for phenol, to yield cresols and methyl-anisoles. The latter reaction was favoured over the disproportion of anisole in the presence of phenol [5]. An important contribution to $C$-alkylated compounds also derived from the intra-molecular rearrangement of anisole into o-cresol [9]. The exchange of protons with $\mathrm{Na}$ or the poisoning with $\mathrm{NH}_{3}$ led to an increase of the anisole/cresols ratio, indicating that anisole formation required sites with lower acid strength as compared to those needed for cresol formation [6], in agreement with what proposed formerly by Namba et al [10]. Similar results were obtained by other authors [7-9]. 
The reactivity of Al-MCM-41 also is imilar to that of $\mathrm{H}-\mathrm{Y}$ [39], with anisole acting as a reaction intermediate. The mechanism of reaction, involving the direct formation of anisole and cresols and the consecutive transformation of anisole, was recently confirmed by means of in-situ measurements by Weitkamp et al. [54].

With Beta zeolites, again the formation of anisole and cresols occurred through parallel reactions $[22,23]$. Anisole then was the intermediate in the formation of cresols. As for the effect of the Si/Al ratio, higher ratios implied a lower phenol conversion and hence a greater selectivity to anisole. No effect of shape-selectivity was found.

As for the electrophylic substitution on phenol, the active species is generated by adsorption of methanol and formation of framework-bound methoxonium $\left(\mathrm{CH}_{3} \mathrm{OH}_{2}{ }^{+}\right)$ion and methoxy species, which can coexist at low temperature. However, at higher temperature the equilibrium is shifted towards the methoxy species [55], which acts as the electrophylic alkylating agent on alkylaromatics [56,57].

\subsubsection{Performance of beta-2 and beta-3 catalysts in phenol methylation}

The effect of time-on-stream on conversion of phenol in methylation over the beta-2 catalyst, at four different temperatures, is reported in Fig.10, whereas Fig.11 shows the corresponding distribution of products, as measured at $450^{\circ} \mathrm{C}$. The following considerations are of relevance: $i)$ There is a considerable deactivation of catalyst with increasing time-on-stream. ii) Initial conversion is $100 \%$ at temperature higher than $320^{\circ} \mathrm{C}$, whereas it approaches $75 \%$ at $320^{\circ} \mathrm{C}$. iii) Deactivation rate appears substantially independent of temperature. iv) Deactivation is accompanied by a change in the relative amount of products. Specifically, at total conversion the main products are poly-alkylated compounds (mainly di- and tri-methyl phenols and methyl and di-methyl anisoles), whereas the progressive decrease of conversion leads to a rapid decrease of the latter compounds, with a corresponding increase of primary alkylation products: anisole, o-cresol 
and $p$-cresol. Amongst the latter, the prevailing one is o-cresol. $v$ ) A more detailed investigation of the trend of products formation indicates that the selectivity to cresols decreases monotonously when conversion increases, whereas the selectivity to anisole decreases more rapidly. This is because the cresols undergo consecutive reactions of transformation to diphenols, whereas anisole not only undergoes the analogous consecutive alkylation to methyl-anisole, but also it acts as an alkylating agent by itself. Indeed, it is known that anisole can either rearrange to o-cresol (intra-molecular rearrangement) or act as an inter-molecular alkylating agent, with co-generation of phenol $[5,9,39,54]$. vi) At lower temperatures the distribution of products is similar to that obtained at $450^{\circ} \mathrm{C}$. The only difference is the selectivity ratio between anisole and cresols.

It is worth noting that in the alkylation of alkylbenzenes (e.g., of toluene) with methanol it is possible to obtain a high selectivity to the para- $C$-alkylated compound. By contrast, in the alkylation of activated arenes, such as phenol, diphenols and aniline, with olefins or with alcohols, the selectivity for the para-electrophilic substitution is lower than expected [58]. Indeed, on amorphous acid catalysts, the selectivity to o-cresol can even approach $100 \%[8,59,60]$. The low selectivity to $p$-cresol in phenol methylation has been attributed to different reasons $[61,62]$ and specifically: $ı$ ) The alkylation at heteroatom is an intermediate step in $C$-alkylation by the olefin or by the alcohol [63]. ii) An interaction exists between the alkylating agent and the oxygen atom of phenol, which favours the alkylation at the ortho position [5,63]. iii) A reaction between adsorbed anisole, which acts as the alkylating agent, and gas-phase phenol can be hypothesised [8], in which the interaction between the two $\mathrm{O}$ atoms puts the methyl group of anisole closer to the ortho position of phenol. iv) Furthermore, even in the homogeneous acid-catalysed electrophylic substitution on phenols, usually ortho/para ratios higher than the statistic value $2 / 1$ are found $[58,64]$. This implies that adsorptive/geometric effects are not the main reason for the regioselectivity observed. 
So, the overall mechanism for the acid-catalysed methylation of phenol [8] includes the direct $C$-alkylation at the ortho and para positions (in confined environments the direct para- $\mathrm{C}$-alkylation can be preferred) and the $\mathrm{O}$-alkylation to yield anisole, the ratio $\mathrm{C}$-/Oalkylation being a function of the catalyst acid strength. The secondary, consecutive intramolecular rearrangement of anisole to $O$-cresol makes the final ortho/para- $C$-alkylation ratio to become very high, especially over less acidic catalysts (e.g., on amorphous materials).

The performance of the beta-3 catalyst is summarized in Fig.12 (effect of time-onstream on conversion of phenol, at four temperatures) and Fig.13 (effect of time-on-stream on distribution of reaction products, at $450^{\circ} \mathrm{C}$ ). The comparison with the data obtained with beta-2 zeolite (Fig.10 and 11) highlights that: $I$ ) The initial activity of the beta-3 zeolite is greater than that of beta-2. This is evident for the runs at $320^{\circ} \mathrm{C}$ only, since higher temperatures lead to total or almost total conversion for both catalysts. This difference is very likely due to the higher intra-particle residence time of reactants in the larger crystal size zeolite. ii) At higher temperatures the deactivation rate seems not much affected by crystal size. Only at 320 and $350^{\circ} \mathrm{C}$ the beta-2 zeolite seems to exhibit a quicker deactivation rate than beta-3. This is likely due to the shorter mean path within smaller zeolite crystals, whose pores become obstructed more quickly than the longer pores of beta-3. Since the difference is evident at low temperature only, this means that the species responsible for deactivation are not the alkyl-aromatics formed by methanol transformation (the formation of which is favoured at high temperature), but more likely phenol and oxygenated products, the diffusion of which is slower at lower temperature, due to their low volatility and to their stronger interaction with the zeolite acid sites. The characterisation of spent catalysts (vide supra) confirm this hypothesis. iii) The nature of products and the effect of conversion and of temperature on selectivity do not differ significantly from those observed with beta-2 catalyst. 
At last, Fig.14 shows the effect of phenol conversion on the anisole/cresols ratio at 320 , 390 and $450^{\circ} \mathrm{C}$ on beta- 2 and beta- 3 catalysts. One may see that: I) The ratio decreases with increasing conversion, due to the secondary, consecutive transformations occurring on anisole, with formation of additional cresols; ii) The ratio decreases when increasing temperature at any conversion level, showing that low temperature favours the primary methylation at oxygen (and hence to anisole), with respect to the primary methylation at aromatic carbons.

Even though the comparison between zeolites is arguable when done under conditions that lead to catalyst deactivation and coke accumulation, nevertheless the data of Fig. 14 indicate that the anisole/cresols ratio with beta-3 zeolite is systematically lower than for beta- 2 at any conversion level and at any temperature. This means that the extent of the consecutive transformation of anisole to cresols is higher in the larger crystal size zeolite, as a consequence of the longer permanence of anisole within the zeolite pores, favouring both the secondary, consecutive intra-molecular rearrangement and inter-molecular alkylation of anisole.

An effect of crystal size on products distribution was also reported by Moon et al for phenol methylation over MCM-22 [12]. The authors found that $p$-cresol formed preferentially with respect to o-cresol, especially in the case of catalysts where the zeolite crystal sizes were greater than $1 \mu \mathrm{m}$. It was thus proposed that in the case of MCM-22 the $10 \mathrm{MR}$ pores allow easy diffusion of $p$-cresol and that the effect of this phenomenon is enhanced when the crystal size is relatively large. Also in the case of cresols isomerisation, the distribution of isomers (the formation of which occurs both by intramolecular methyl shift and bimolecular disproportionation) was governed by product desorption/diffusion. Shape selectivity favoured monomolecular reactions [65].

\subsubsection{Transformation of methanol into poly-alkylated benzenes}


During reaction with phenol, methanol also undergoes a parallel transformation to olefins and alkylbenzenes. The relative amount of the two classes of compounds is a function of the reaction temperature, higher temperatures favouring the formation of the latter compounds. Therefore, we also investigated the formation of alkylbenzenes. The yield to these compounds is shown in Fig.s 15 and 16, for the beta-2 and beta-3 catalysts, respectively, as a function of time-on-stream at $450^{\circ} \mathrm{C}$. The same Figures also report the conversion of methanol, which also includes the amount converted for phenol methylation. It is worth noting that no "light" products of methanol decomposition (i.e. $\mathrm{CO}, \mathrm{CO}_{2}, \mathrm{H}_{2}$ ) formed.

The principal products coming from methanol transformation were toluene, pentamethylbenzene and hexamethylbenzene. The yield to these compounds was relevant and the greater fraction of methanol was converted to poly-alkylated benzenes, rather than being involved in phenol methylation. This aspect has never been reported in the literature dealing with the gas-phase methylation of phenol catalysed by zeolites. Furthermore, it is evident that this is one reason for the need of feeding a large excess of methanol with respect to the stoichiometric requirement for the mono-alkyation of phenol. The competitive reaction of methanol transformation to alkylbenzenes makes the amount of methanol available for phenol methylation to become very low.

The conversion of methanol increased during the elapsing reaction time, due to the increased formation of poly-alkylated compounds, whereas, at the opposite, the amount of methanol that reacts with phenol decreased (see Figs. 10 and 12). Therefore, it seems that the active sites for the formation of these compounds are generated during reaction, while the sites responsible for the generation of the active species for the electrophilic substitution at the phenol ring are progressively poisoned. This clearly indicates that the mechanism of the two reactions is different. The conversion of methanol reached a maximum at approximately 800-1000 minutes-on-stream, after which it rapidly fell down, 
likely because of the considerable amount of coke accumulated in the catalyst, due to the growth of poly-nuclear aromatics.

The behaviour of the two zeolites was not much different, a part from the slightly different value of time-on-stream at which the maximum methanol conversion was attained (700 min for beta-2, against 1000 min for beta-3). This is probably due to the larger crystal size of the latter sample, that made pore filling by coke to take longer time than with the former sample. With both samples the yield to toluene decreased, whereas that to pentamethylbenzene showed a maximum before the reaction time needed to reach the highest methanol conversion. The yield to the totally alkylated compound (hexamethylbenzene) increased, until the maximum methanol conversion was reached. This indicates that the growth of the molecular weight occurred in a consecutive-steps network fashion.

The mechanism for the formation of alkylated benzenes by self-reaction of methanol over zeolites (the MTG process) includes one first step of dehydration of methanol to dimethylether. Two mechanisms have been proposed, either an indirect pathway, in which the adsorbed methanol reacts with the methoxy species, which then reacts with another methanol molecule to dimethylether [66], or the direct pathway, in which two methanol molecules react over an acid site, with the formation of dimethylether and $\mathrm{H}_{2} \mathrm{O}$ in one step [67]. The surface methoxy species $\mathrm{SiO}\left(\mathrm{CH}_{3}\right) \mathrm{Al}$ has been demonstrated to play a role in the formation of dimethylether [68]. The further conversion of the equilibrium mixture of methanol and dimethylether (and water as well) is dominated by a "hydrocarbon pool" route $[69,70]$, in which methanol is directly added onto reactive organic compounds to form aliphatic and aromatic hydrocarbons. The methoxy species also plays a role in the kinetic "induction period", leading to the reactive hydrocarbon pool.

Alternative "direct" mechanisms have been proposed, in which either a carbenium ion $\left(\mathrm{CH}_{3}{ }^{+}\right)$reacts with dimethylether to generate either a carbonium ion $\left(\mathrm{CH}_{3}-\mathrm{CH}_{3}{ }^{+}-\mathrm{OCH}_{3}\right)$, or 
an oxonium ylide species. Other mechanisms include a carbene species $\left(: \mathrm{CH}_{2}\right)$ as the reaction intermediate (see the review by Haw et al. [71] for an analysis of the several mechanisms proposed in literature). The methoxy species acts as an alkylating agent in the presence of aromatic compounds. Furthermore, at $\mathrm{T}>170^{\circ} \mathrm{C}$, hydrogen atoms are abstracted by basic oxygen atoms of the framework, with formation of surface-stabilized intermediates of ylide or carbene nature [72], which are responsible for the methylation of aliphatic compounds, and for the formation of hydrocarbons, both aliphatic and aromatic (polymethylbenzenes) [73].

In the case of Beta zeolites, the predominant aromatic compounds in methanol transformation at high $\mathrm{T}$ are hexamethylbenzenes and pentamethylbenzenes (in full agreement with our results), while ZSM-5 gave mostly dimethyl and trimethylbenzenes [74]. These compounds can be further converted to naphthalene derivatives, which are finally responsible for the formation of coke precursors and of zeolite deactivation [21].

Our data support the need for an induction period for the formation of these compounds, associated to the generation of a "hydrocarbon pool". This corresponds to the progressive increase of methanol transformation into poly-alkyl benzenes shown in Fig.s 15 and 16. The progressive transformation of the hydrocarbon pool into heavier and heavier poly-alkylated compounds and to coke eventually leads to the complete deactivation of the catalyst.

\subsubsection{Coke composition}

Thermogravimetric (TG) analysis showed that the weight loss due to burning out of coke components by calcination in air amounted to $3.4 \%$, while for beta-2 it was considerably higher, $12.8 \%$. This obviously relates to the higher acidity of beta-2 as compared to beta-1. The organic matter extracted from beta-2 with $\mathrm{CH}_{2} \mathrm{Cl}_{2}$ amounted to $12.7 \%$, perfectly in line with the value determined by TG. The GC-QMS analysis of the 
extracted fraction showed the presence of the following compounds: phenol (8 mol\%), 0 and p-cresols (4\%), dimethyl-phenols (8\%), trimethyl-phenols (15\%), tetramethy-phenols (18\%), pentamethyl-benzene (5\%), hexamethyl-benzene $(5 \%)$, 3-ethyl-5-methyl-phenol (1\%), 2-hydroxyphenyl-phenylmethanone (15\%), 2-methyl-5-(1-methylethyl)-phenol (6\%), 1-methoxy-4-methyl-2-(1-methylethyl)-benzene (15\%). In the case of beta-1, instead, the following compounds were identified: phenol, cresols, dimethyl-phenols, trimethyl-phenols, tetramethyl-phenols and (dimethyl-ethyl)-phenols. Therefore, with the latter catalyst there was substantially no formation of poly-alkylbenzenes, i.e. the species coming from the transformation of methanol. With both catalysts, the insoluble coke recovered after dissolution of the zeolite was almost weightless and presumably composed of high-MW polynuclear species, their very low amount preventing however any reliable quantitative determination.

Therefore, these data indicate that the presence of strong acid sites in beta- 2 is responsible for the formation of poly-alkylbenzenes, while silanols (present in both beta-1 and beta-2 samples, though in lower concentration in the former catalyst) are strong enough to catalyse the reaction of phenol methylation. This also indicates that the active methanol species able to attack phenol to yield methylated phenol is different from the species self-reacting to yield poly-alkylbenzenes. Indeed, on one hand the latter species can form only on acid sites much stronger than those required to form the former. On the other hand, the former species, though being not able to generate poly-alkylbenzenes, is electrophylic enough to react with phenol.

Furthermore, beta-1 was less active than beta- 2 and beta-3, but did exhibit a deactivation rate comparable to that of the latter catalysts. This indicates that the main reason for catalyst deactivation in phenol methylation is associated to the build-up in catalyst pores of oxygen-containing species (phenol and alkylated phenol compounds). It is worth noting that the analysis of the compounds retained in the pores showed a high 
concentration of heavier compounds (poly-alkylated phenol), that instead are present in low concentration in the reactors' outcoming products stream. Therefore, heavier phenol derivatives are the species that more accumulate in the porous structure, as expected, due to their more cumbersome structure.

Therefore, two different deactivation mechanisms can be envisaged. One mechanism, responsible for the progressive deactivation of the catalyst in the methylation of phenol, is due to the retention of heavy, oxygenated compounds (i.e., poly-alkylated phenols). This derives from the strong interaction of phenol and phenol derivatives with the active sites, which establishes from the very beginning of the reaction and hinders the generation of the active species responsible for the electrophylic attack to the phenol aromatic ring. Despite this, methanol conversion progressively increases during the first hours-on-stream, due to the fact that methanol is simultaneously converted to alkyl and poly-alkyl benzenes, generated from the building up of the "hydrocarbon pool" inside pores. This is supported also by the change in the nature of the alkyl benzenes forming along with increasing methanol conversion. However, the progressive hardening of these species generates poly-nuclear aromatics, which in a few hours fills up the pores and eventually deactivates the catalyst.

\section{CONCLUSIONS}

The systematic analysis carried out in the present work allowed to throw light on several aspects of the methylation of phenol, from many points of view, ranging from catalyst structure, crystal size and surface acidity characteristics, to energetics of interaction between methanol (and water) and acid sites, to the effect of all these characteristics on kinetics and on mechanistic features of the catalytic reaction and of 
catalyst deactivation phenomena. The main conclusions one can draw from the present results are the following:

1. High Si/Al ratio BEA-structured zeolite in protonated form is a very active catalyst for the methylation of phenol, leading to cresols and anisole as primary products, which rapidly methylate to poly-alkylated phenols. As deactivation proceeds, the selectivity to cresols and anisole increases substantially, together with a rapid decrease of selectivity to poly-alkylated species.

2. In this protonated zeolite acidity is prevalently of Brønsted type, independently of zeolite crystal size. However, the main part of the acid sites are of medium-to-lowstrength. Indeed, high-strength Lewis-type sites are either almost absent, especially when metal cations partially substitute for protons, or seem to play a role prevalently in catalyst deactivation.

3. Stacking faults in the zeolite framework, generated by the intergrowth of at least two BEA polymorphs, can increase the concentration of relatively low-strength silanolsbased acid sites, which seem however sufficiently active to trigger the phenol methylation primary reaction.

4. Deactivation is originated essentially by phenol and poly-alkylated phenolderivatives. Self oligomerisation-cyclisation of methanol to olefins and aromatics, followed by further alkylation to aromatic $\mathrm{C}$ atoms, contributes more significantly to catalyst deactivation only for time-on stream values longer than a few hours.

5. At higher temperature all the zeolites deactivate at a comparable rate, whereas at lower temperature initial catalytic activity is higher for larger crystal size zeolite, due to the longer diffusion time of reactants within longer zeolite pores, favouring a longer contact with active sites.

6. At any conversion level and at any temperature the anisole/cresols ratio is systematically lower for the larger crystal size zeolite, since the secondary 
transformations of anisole to cresols by both intra-molecular rearrangement and inter-molecular alkylation of phenol is favoured by the longer residence time of anisole within the zeolite pores.

\section{REFERENCES}

1. Ullmann's Encyclopedia of Industrial Chemistry, $6^{\text {th }}$ Edition, Wiley-VCH, Weinheim (2003), Vol.9, p.642

2. P.D. Chantal, S. Kaliaguine, J.L. Grandmaison, Appl. Catal., 18 (1985) 133

3. R. Pierantozzi, A.F. Nordquist, Appl. Catal., 21 (1986) 263

4. S.C. Lee, S.W. Lee, K.S. Kim, T.J. Lee, D.H. Kim, J.Chang Kim, Catal. Today, 44 (1998) 253

5. M. Marczewski, J.-P. Bodibo, G. Perot, M. Guisnet, J. Molec. Catal., 50 (1989) 211

6. L. Garcia, G. Giannetto, M.R. Goldwasser, M. Guisnet, P. Magnoux, Catal. Lett., 37 (1996) 121

7. S. Balsamà, P. Beltrame, P.L. Beltrame, P. Carniti, L. Forni, G. Zuretti, Appl. Catal., 13 (1984) 161

8. P. Beltrame, P.L. Beltrame, P. Carniti, A. Castelli, L. Forni, Appl. Catal., 29 (1987) 327

9. R.F. Parton, J.M. Jacobs, H. van Ooteghem, P.A. Jacobs, Stud. Surf. Sci. Catal., 46 (1989) 211

10.S. Namba, T. Yashima, Y. Itaba, N. Hara, Stud. Surf. Sci. Catal., 5 (1980) 105

11.Z.-H. Fu, Y. Ono, Catal. Lett., 21 (1993) 43

12. G. Moon, W. Böhringer, C.T. O'Connor, Catal. Today, 97 (2004) 291

13. M.D. Romero, G. Ovejero, A. Rodriguez, J.M. Gomez, I. Agueda, Ind. Eng. Chem. Res., 43 (2004) 8194

14.G. Sarala Devi, D. Giridhar, B.M. Reddy, J. Molec. Catal., 181 (2002) 173

15. F.M. Bautista, J.M. Campelo, A. Garcia, D. Luna, J.M. Marinas, A. Romero, J.A. Navio and M. Macias, Appl. Catal., A, 99 (1993) 161

16. R. Bal, B.B. Tope, S. Sivasanker, J. Mol. Catal. A, 181 (2002) 161

17.S. Velu, C.S. Swamy, Appl. Catal. A, 145 (1996) 141

18. V.V. Rao, V.Durgakumari, S. Narayanan, Appl. Catal., 49 (1989) 165

19.S. Velu, C.S. Swamy, Appl. Catal. A, 162 (1997) 81 
20. M. Bolognini, F. Cavani, D. Scagliarini, C. Flego, C. Perego, M. Saba, Catal. Today, 75 (2002) 103

21. M. Bjørgen, U. Olsbye, S. Kolboe, J. Catal., 215 (2003) 30

22.J. Xu, A.-Z. Yan, Q.-H. Xu, React. Kinet. Catal. Lett., 62 (1997) 71

23. G. Chen, X. Liu, Chin. J. Catal., 19 (1998) 427

24. K. K. Cheralathan, I. S. Kumar, M. Palanichamy, V. Murugesan, Appl. Catal. A, 241 (2003) 247

25. A. V. Krishnan, K. Ojha, and N. C. Pradhan, Org. Proc. Res. Dev., 6 (2002) 132

26. K. Zhang, C. Huang, H. Zhang, S. Xiang, S. Liu, D. Xu, H. Li, Appl. Catal. A, 166 (1998) 89

27. E. Dumitriu, V. Hulea, J. Catal., 218 (2003) 249

28. I.Kiricsi, C.Flego, G.Pazzuconi, W.O.Parker, Jr., R.Millini, C.Perego, G.Bellussi, J.Phys.Chem., 98 (1994) 4627

29. G.Bellussi, G.Pazzuconi, C.Perego, G.Girotti, G.Terzoni, J.Catal., 157 (1995) 227

30.G.Perego, S.Amarilli, R.Millini, G.Bellussi, G.Girotti, G.Terzoni, Mesop. Mater., 6 (1996) 395

31. G.Girotti, EurpaCat-IV, Rimini, Sept. 5-10, 1997, Book of Abstracts, KN11

32. J. Pérez-Pariente et al., Appl. Catal., 31 (1987) 35

33. M.A. Camblor, J. Pérez-Pariente, Zeolites, 11 (1991) 202

34.U.S. Patent 5,453,511, Sept. 26,1995

35. V. Bolis, B. Fubini, L. Marchese, G. Martra, D. Costa, J.Chem.Soc., Faraday Trans. 1991, 87, 497

36. V. Bolis, A. Cavenago, B. Fubini, Langmuir 1997, 13, 895

37. V. Bolis, C. Busco, S. Bordiga, P. Ugliengo, C. Lamberti, A. Zecchina, Appl. Surf. Sci. 2002, 196, 56

38. V. Bolis, C. Busco, P. Ugliengo, J. Phys. Chem. B, in press

39. K. G. Bhattacharyya, A.K. Talukdar, P. Das, S. Sivasanker, J. Molec. Catal. A, 197 (2003) 255

40. P. Magnoux, P. Roger, C. Canaff, V. Fouché, N.S. Gnep, M. Guisnet, Stud. Surf. Sci. Catal., 34 (1987) 317

41. R.L. Wadlinger, G.T. Kerr, E.J. Rosinski, U.S. Patent 3,308,069 (1967) and reissued U.S. Pat. Re 28,431 (1975) assigned to Mobil Oil Corp

42.J.M. Newsam, M.M.J. Treacy, W.T. Koetsier, C. De Gruyter, Proc. R. Soc. London A, $420(1988) 375$ 
43. J.B. Higgins, R.B. La Pierre, J.L. Schlenker, A.C. Rohrman, J.D. Wood, G.T. Kerr, W.J. Rohrbaugh, Zeolites, 8 (1988) 446

44. C. Pazè, S. Bordiga, C. Lamberti, M. Salvalaggio, A. Zecchina, J. Phys. Chem. B 101, (1997) 4740-4751.

45. A. Zecchina, S. Bordiga, G. Spoto, D. Scarano, G. Spanò, F. Geobaldo, J. Chem. Soc., Faraday Trans., 9 (1996) 4863-4875.

46. S. Bordiga S., L. Regli, D. Cocina, C. Lamberti, C. M. Bjørgen, K.P. Lillerud, J. Phys. Chem. B, 109, (2005) 2779-2784

47.G.Herzberg, Molecular Spectra and Molecular Structure, F. R. S.-II. Infrared and Raman Spectra of Polyatomic Molecules; D. Van Nostrand Company, Inc.: New York, 1945; p 216.

48. S. E. Odinokov, A. V. Jogansen, Spetrochim. Acta, Part A, 28 (1972) 2343-2350.

49.N. B. Coltup, L. H.; Daly, S. E Wiberley, Introduction to infrared and Raman Spectroscopy; Academic Press: London, 1995; p 220.

50. S. F. Boys, F. Bernardi, Mol. Phys. 1970, 553

51. V. Bolis, M. Broyer, A. Barbaglia, C. Busco, G. M. Foddanu, P. Ugliengo, J. Molec. Catal., A: Chemical, 204 (2003), 561

52. G. Busca, Phys. Chem. Chem. Phys. 1 (1999) 723.

53. M. Renaud, P.D. Chantal, S. Kaliaguine, Canad. J. Chem. Eng., 64 (1986) 787

54.W. Wang, P. L. De Cola, R. Glaeser, I.I. Ivanova, J. Weitkamp, M. Hunger, Catal. Lett 94 (2004) 119

55. J. Rakoczy, T. Romotowski, Zeolites, 13 (1993) 256

56. G. Mirth, J. Lercher, J. Catal., 132 (1991) 244

57. A. Corma, G. Sastre, P.M. Viruela, J. Mol. Catal. A, 100 (1995) 75

58. R.F. Parton, J.M. Jacobs, D.R. Huybrechts, P.A. Jacobs, Stud. Surf. Sci. Catal., 46 (1989) 163 , and references therein

59. J.M. Campelo, A. Garcia, D. Luna, J.M. Marinas, M.S. Moreno, Stud. Surf. Sci. Catal., 41 (1988) 249

60. J.M. Campelo, A. Garcia, D. Luna, J.M. Marinas, M.S. Moreno, Bull. Soc. Chim. France, 2 (1988) 283

61.P. Espeel, R. Parton, H. Toufar, J. Martens, W. Hölderich, P. Jacobs, in "Catalysis and Zeolites. Fundamentals and Applications", J. Weitkamp and L. Puppe (Eds.), Springer, Berlin, 1999, Ch. 6, p.377

62.J.B. Moffat, Catal. Rev. Sci. Eng., 18 (1978) 199 
63. M. Marczewski, G. Perot, M. Guisnet, Stud. Surf. Sci. Catal., 41 (1988) 273

64.Patai "The Chemistry of the Hydroxyl Group", Interscience Publ. John Wiley \& Sons, (1971) 414

65. F.E. Imbert, M. Guisnet, F. Gnep, J. Catal., 195 (2000) 279

66. T.R. Forester, R.F. Howe, J. Am. Chem. Soc., 109 (1987) 5076

67. J. Bandiera, C. Naccache, Appl. Catal., 69 (1991) 139

68. W. Wang, M. Seiler, M. Hunger, J. Phys. Chem. B, 105 (2001) 12553

69. I.M. Dahl, S. Kolboe, J. Catal., 149 (1994) 458

70. B. Arstad, S. Kolboe, J. Am. Chem. Soc., 123 (2001) 8137

71.J.F. Haw, W. Song, D.M. Marcus, J.B. Nicholas, Acc. Chem. Res., 26 (2003) 317

72.P.E. Sinclair, C.R.A. Catlow, J. Phys. Chem. B, 101 (1997) 295

73. W. Wang, A. Buchholz, M. Seiler, M. Hunger, J. Am. Chem. Soc., 125 (2003) 15260

74.Ø. Mikkelsen, S. Kolboe, Microp. Mesop. Mater., 29 (1999) 173

\section{ACKNOWLEDGEMENTS}

The financial aid of INSTM, through the Prisma 2002 programme is gratefully acknowledged. We are also indebted with dr A.Casalini, Stazione Sperimentale per i Combustibili (S.Donato Milanese) for the GC-QMS analysis of coke. 


\section{FIGURE CAPTIONS}

Fig.1. XRD patterns of the catalysts prepared. a,b,c refer to polymorphs $A, B$ and $C$ (see ref. 42,43).

Fig. 2 SEM micrographs of: (a) beta-1; $(b)$ beta-2; $(c)$ beta-3; $(d)$ beta-silicalite

Fig.3. a) IR spectra of beta-1, beta-2 and beta-3 zeolites outgassed at $753 \mathrm{~K}$; b) IR spectra of beta-2 and beta-3 zeolites (left and right couple of Figures, respectively). Effect of the interaction with $\mathrm{CH}_{3} \mathrm{OH}$. Top parts of the figure report data related to increasing amounts of methanol, Bottom parts of the figures reports the effect of progressive pumping out at room temperature.

Fig.4: Differential heats of adsorption of $\mathrm{CH}_{3} \mathrm{OH}_{\text {vap. }}$ on beta-2 $(\bullet)$ and beta-3 $(\boldsymbol{\nabla})$ zeolites as a function of the increasing coverage ( $q^{\text {diff }} v s$. $n_{\text {ads }}$ ). Inset: volumetric isotherms, $n_{\text {ads }}$ $\left(\mathrm{CH}_{3} \mathrm{OH}\right.$ molecules/uc) vs. $\mathrm{P}_{\mathrm{CH}} \mathrm{OH}$ equilibrium pressure. Solid symbols: ads. I, open symbols: ads. II. $\mathrm{T}_{\text {ads. }}=303 \mathrm{~K}$

Fig.5: Differential heats of adsorption of $\mathrm{H}_{2} \mathrm{O}_{\text {vap. }}$ on beta-1 ( $)$, beta-2 ( $\bullet$ ), beta-3 $(\boldsymbol{\nabla})$ and beta-silicalite ( $\mathbf{\Lambda})$, in comparison with the commercial catalyst beta-10 ( $\mathbf{-})$, characterized by $\mathrm{Si} / \mathrm{Al}=10$. Inset: volumetric isotherms, $\mathrm{n}_{\text {ads }}\left(\mathrm{H}_{2} \mathrm{O}\right.$ molecules/uc) vs. $\mathrm{p}_{\mathrm{H} 2 \mathrm{O}}$ equilibrium pressure. In both qdiff $v s$. $n_{\text {ads }}$ and $\mathrm{n}_{\text {ads }} v s$. peq plots only the first run data (ads. I) are reported. $T_{\text {ads. }}=303 \mathrm{~K}$

Fig.6: Integral molar heats of adsorption $\left[q^{m o l}\right]_{p}=\left(Q^{\text {int }} / n_{\text {ads }}\right)$ as a function of the average crystals size of the catalyst, at two different surface coverage: $\mathrm{n}_{\text {ads }}=2 \mathrm{H}_{2} \mathrm{O}$ molecules/uc (left) and $\mathrm{n}_{\text {ads }}=4 \mathrm{H}_{2} \mathrm{O}$ molecules/uc (right). $\mathrm{T}_{\text {ads. }}=303 \mathrm{~K}$

Fig.7: B3LYP/6-31+G(d,p) optimized structures of the clusters adopted to mimic the Lewis site interacting with $\mathrm{CH}_{3} \mathrm{OH}(a)$ and $\mathrm{H}_{2} \mathrm{O}$ molecule $(b)$. Binding energies $(\mathrm{BE}, \mathrm{kJ} / \mathrm{mol})$ corrected for the basis set superposition error. Bonds between Al and the oxygen atom of the adsorbed molecule shown as dotted lines.

Fig.8. FT-IR spectra of beta-1 catalyst after saturation with pyridine followed by evacuation at progressively increasing temperature.

Fig.9. FT-IR spectra of beta-2 catalyst after saturation with pyridine followed by evacuation at progressively increasing temperature.

Fig.10. Effect of time-on-stream on conversion of phenol in alkylation over beta-2 catalyst at four different temperatures.

Fig.11. Effect of time-on-stream on products distribution in alkylation of phenol $¥$ over beta2 catalyst. $\mathrm{T}=450^{\circ} \mathrm{C}$.

Fig.12. Effect of time-on-stream on conversion of phenol in alkylation over beta-3 catalyst at four different temperatures.

Fig.13. Effect of time-on-stream on products distribution in alkylation over beta-3 catalyst. $\mathrm{T}=450^{\circ} \mathrm{C}$. 
Fig.14. Effect of phenol conversion on the anisole/cresols molar ratio in alkylation, at $320^{\circ} \mathrm{C}$ (black symbols), $390^{\circ} \mathrm{C}$ (grey symbols) and $450^{\circ} \mathrm{C}$ (white symbols), for the beta-2 (squares) and beta-3 (triangles) catalysts.

Fig. 15. Effect of time-on-stream on methanol conversion and on products distribution in poly-alkylbenzenes formation over beta-2 catalyst. $\mathrm{T}=450^{\circ} \mathrm{C}$. Symbols: $(\bullet)$ methanol conversion; $(\mathbf{O})$ selectivity to toluene, $(\boldsymbol{\square})$ to pentamethylbenzene, $(\mathbf{\Lambda})$ to hexamethylbenzene.

Fig. 16. Effect of time-on-stream on methanol conversion and on products distribution in poly-alkylbenzenes formation over beta-3 catalyst. $\mathrm{T}=450^{\circ} \mathrm{C}$. Symbols as for Fig. 13 . 
Table 1. Main characteristics and energetics of interaction with $\mathrm{H}_{2} \mathrm{O}$ and $\mathrm{CH}_{3} \mathrm{OH}$ of the investigated catalysts

\begin{tabular}{|c|c|c|c|c|c|c|c|c|c|c|}
\hline Cat. & $\begin{array}{c}\mathrm{SiO}_{2} / \mathrm{Al}_{2} \mathrm{O}_{3} \\
\mathrm{~mol} \text { ratio }\end{array}$ & $\begin{array}{c}\mathrm{Si} / \mathrm{Al} \\
\mathrm{mol} \text { ratio }\end{array}$ & $\mathrm{Al} / \mathrm{uc}$ & $\begin{array}{c}\mathrm{av} . \\
\mathrm{cryst.} \mathrm{size} \\
(\mathrm{nm})\end{array}$ & $\begin{array}{c}\mathrm{SSA} \\
\left(\mathrm{m}^{2} / \mathrm{g}\right)\end{array}$ & $\begin{array}{c}\mathrm{V}_{\mathrm{pTOT}} \\
\left(\mathrm{cm}^{3} / \mathrm{g}\right)\end{array}$ & $\begin{array}{c}\mathrm{V}_{\text {pMicr }} \\
\left(\mathrm{cm}^{3} / \mathrm{g}\right)\end{array}$ & $\begin{array}{c}\mathrm{Na}^{+} \\
\mathrm{wt} \%\end{array}$ & $\begin{array}{c}\mathrm{q}_{0} \\
\mathrm{H}_{2} \mathrm{O} \\
\mathrm{kJ} / \mathrm{mol}\end{array}$ & $\begin{array}{c}\mathrm{q}_{0} \\
\mathrm{CH}_{3} \mathrm{OH} \\
\mathrm{kJ} / \mathrm{mol}\end{array}$ \\
\hline beta-1 & 65 & 130 & $\approx 0.5$ & 200 & 481 & 0.343 & 0.239 & 2.42 & 100 & - \\
\hline beta-2 & 77 & 154 & $\approx 0.4$ & 100 & 559 & 0.627 & 0.266 & 0.07 & 160 & 50 \\
\hline beta-3 & 65 & 130 & $\approx 0.5$ & 590 & 565 & 0.324 & 0.299 & 0.01 & 160 & 50 \\
\hline $\begin{array}{c}\text { beta- } \\
\text { silical. }\end{array}$ & 255 & 510 & $<0.1$ & 450 & 529 & 0.311 & 0.270 & $<0.001$ & 80 & - \\
\hline beta-10 & 4.9 & 9.8 & $\approx 6$ & 50 & 360 & - & - & - & 165 & - \\
\hline
\end{tabular}

Table 2: Summary of the most important IR spectroscopic features.

\begin{tabular}{|l|l|l|l|}
\hline IR feature & $\begin{array}{c}|c| \\
\text { beta-1 } \\
\text { frequency }\left(\mathrm{cm}^{-1}\right)\end{array}$ & $\begin{array}{c}\text { beta-2 } \\
\text { frequency }\left(\mathrm{cm}^{-1}\right)\end{array}$ & $\begin{array}{c}\text { beta-3 } \\
\text { frequency }\left(\mathrm{cm}^{-1}\right)\end{array}$ \\
\hline$v(\mathrm{OH})$ isolated silanols & 3740 & 3740 & 3740 \\
\hline $\begin{array}{l}v(\mathrm{OH}) \text { internal and /or } \\
\mathrm{H} \text {-bonded silanols }\end{array}$ & 3670 & 3580 & 3500 \\
\hline$v(\mathrm{OH})$ SiOHAl & Not visible & 3615 & 3613 \\
\hline$v(\mathrm{OH}) \ldots . . \mathrm{OH}-\mathrm{CH} 3$ & Not reported & 3400 & 2100 \\
\hline $\mathrm{A}_{\text {comp }}$ maximum & Not reported & Not revealed & 2900 \\
\hline First Evans window & Not reported & Not revealed & 2720 \\
\hline B comp maximum & Not reported & Not revealed & 2500 \\
\hline Second Evans window & Not reported & Not revealed & 2000 \\
\hline C comp maximum & Not reported & Not revealed & 1600 \\
\hline
\end{tabular}



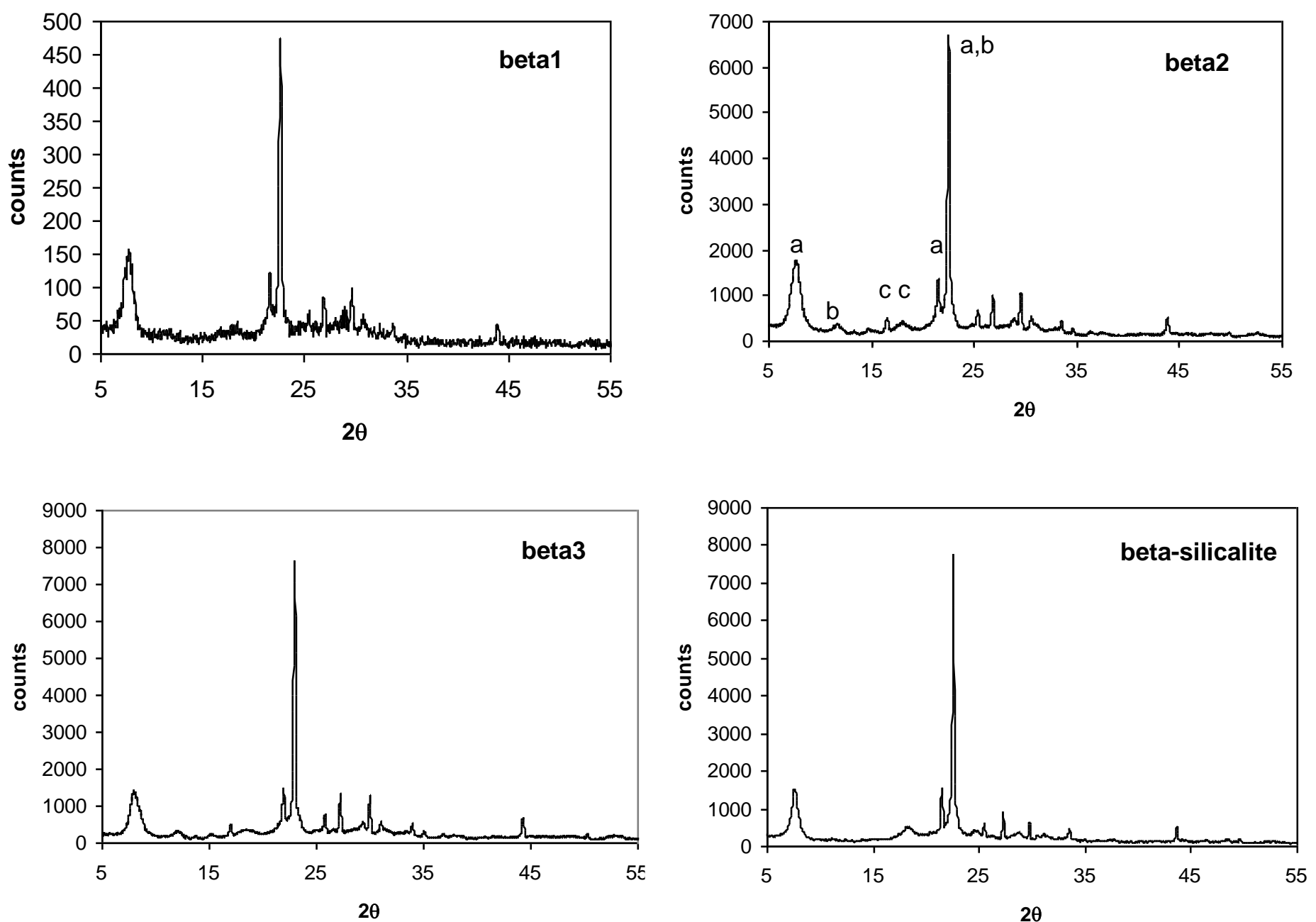

Fig.1 

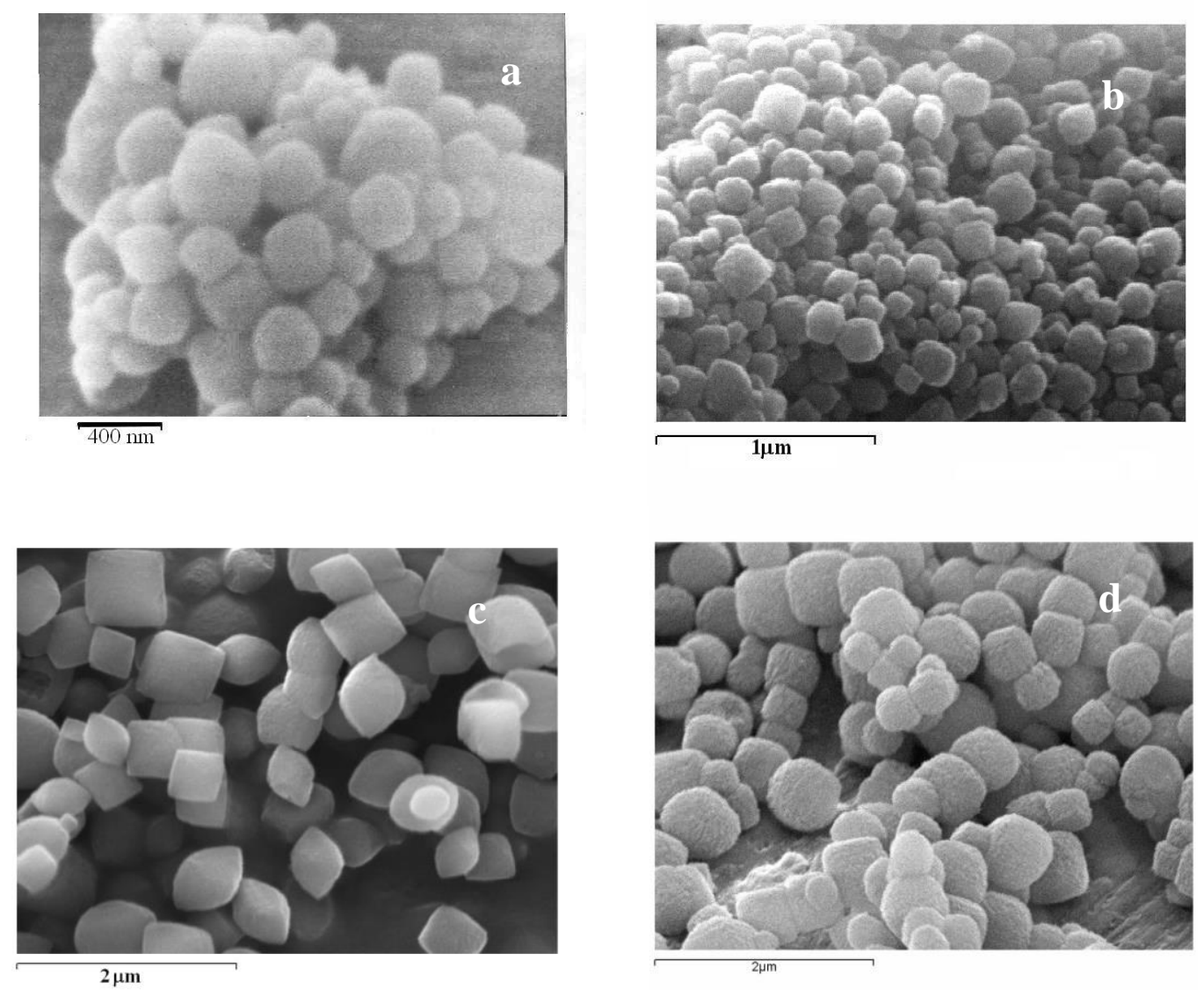

Fig.2 

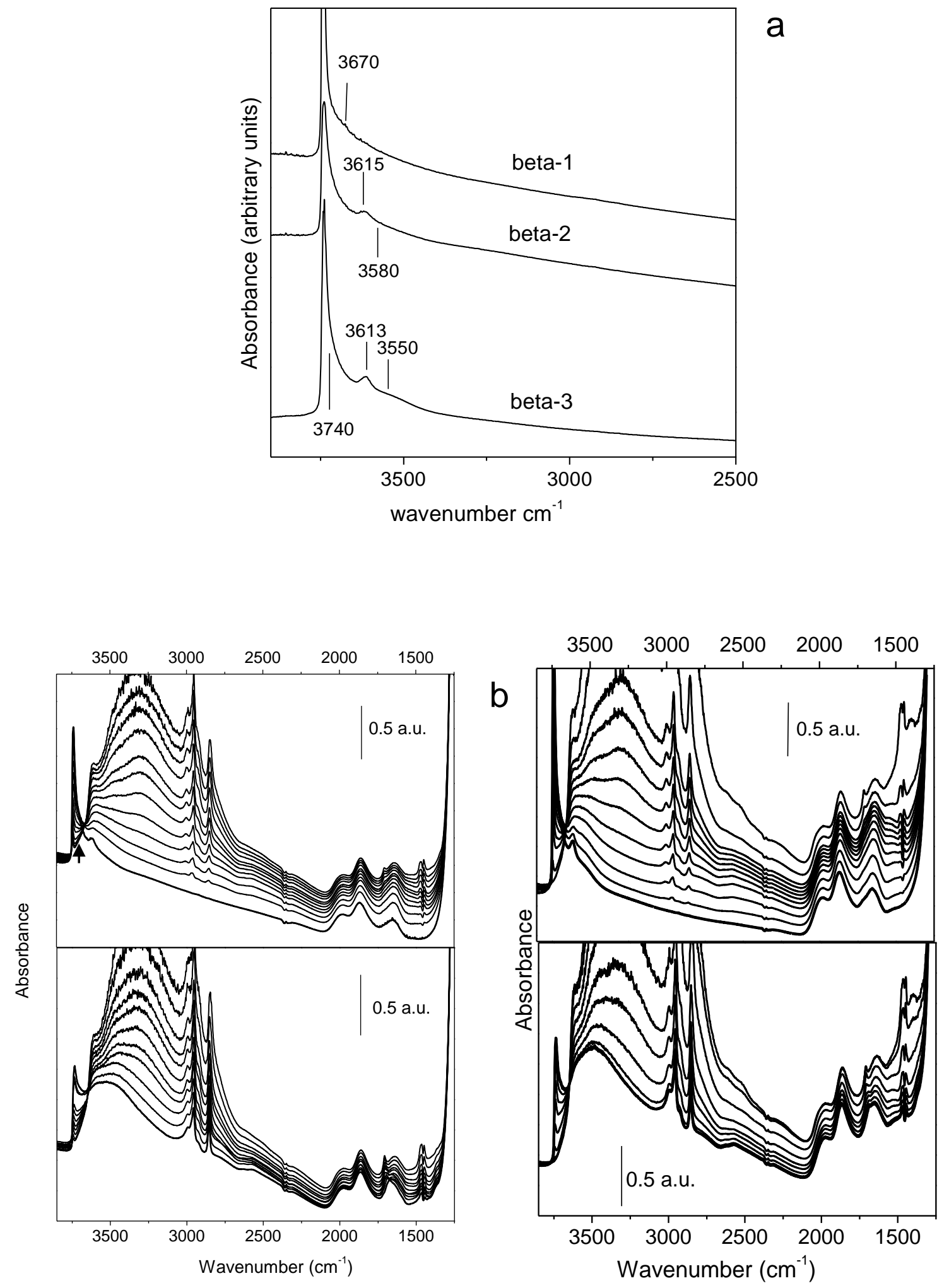

Fig.3 


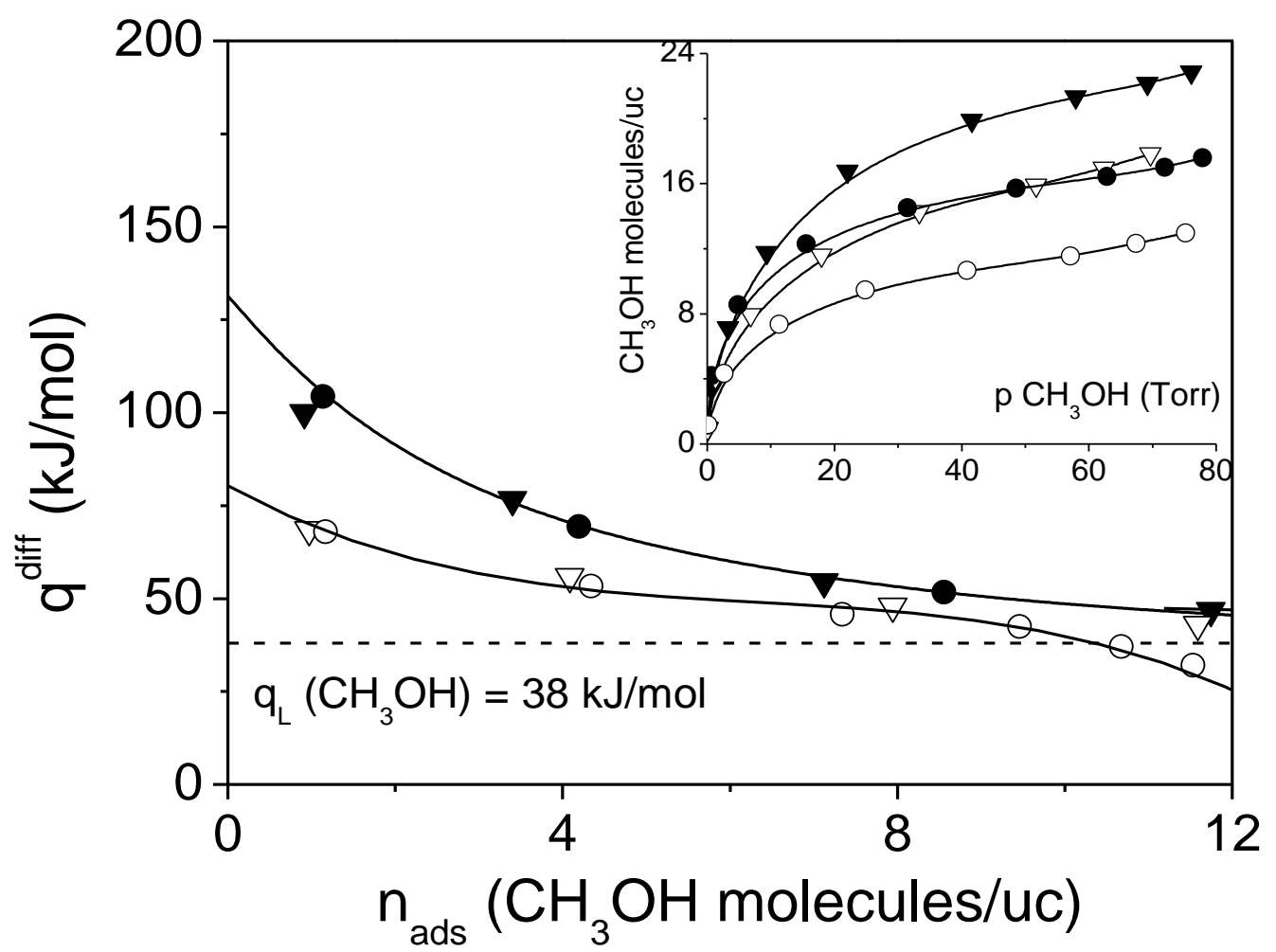

Fig4 


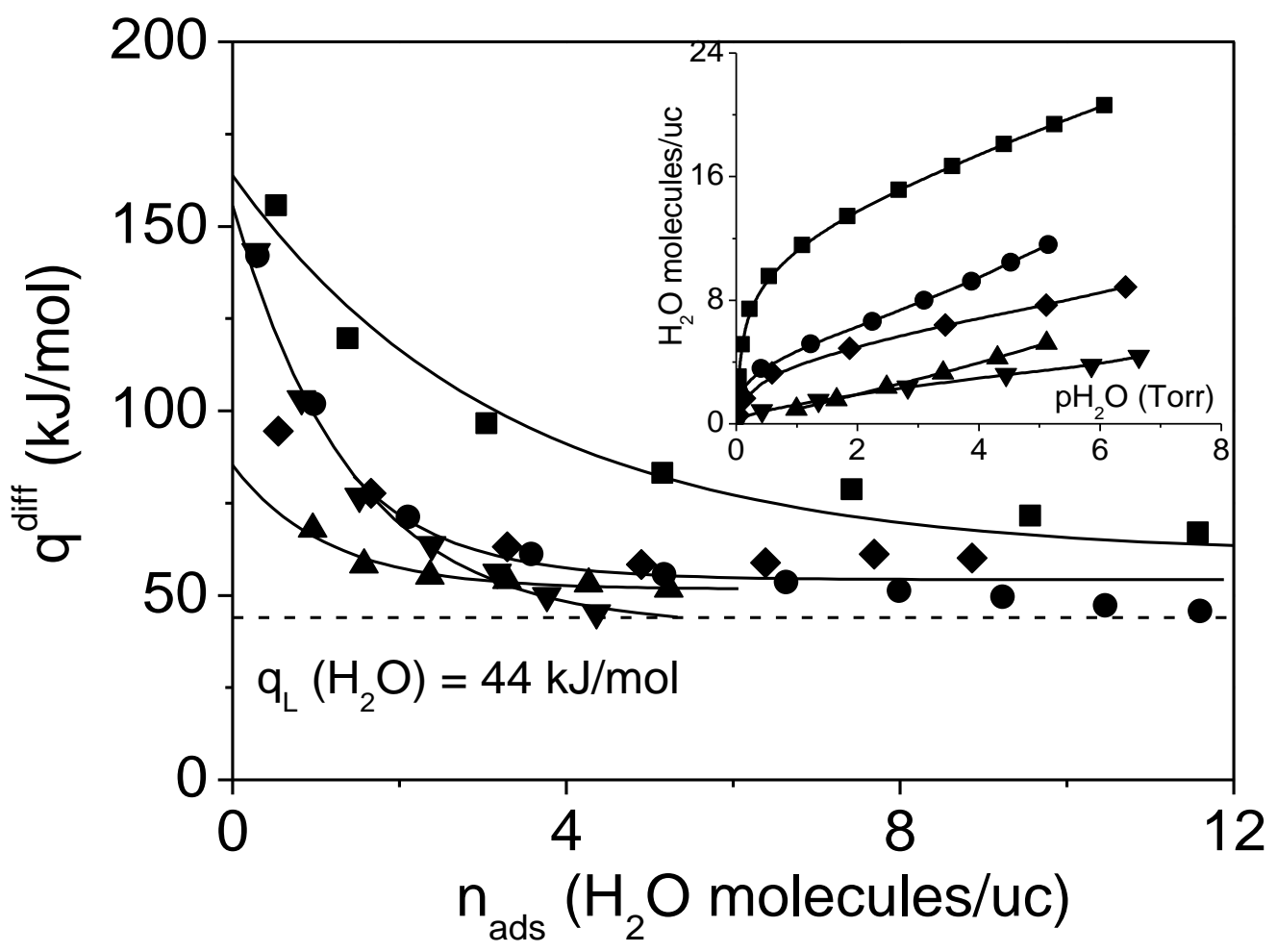

Fig.5 


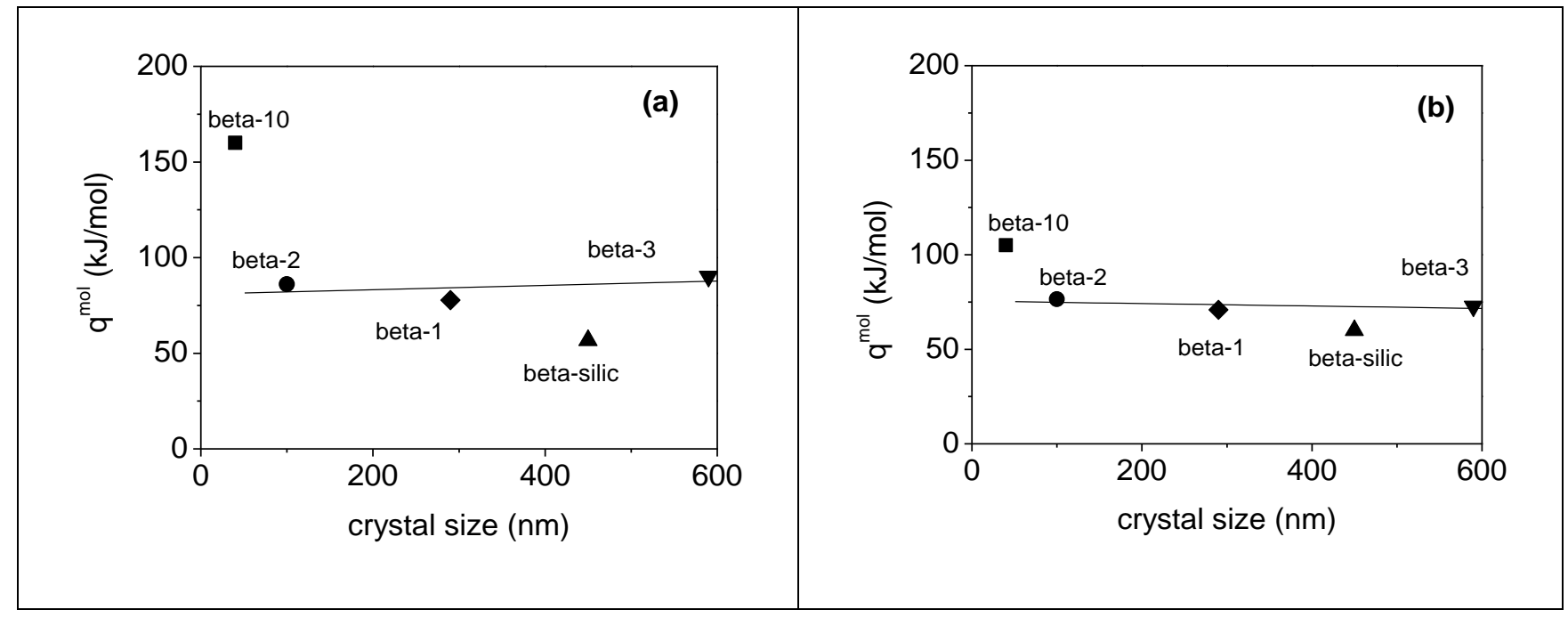

Fig.6 

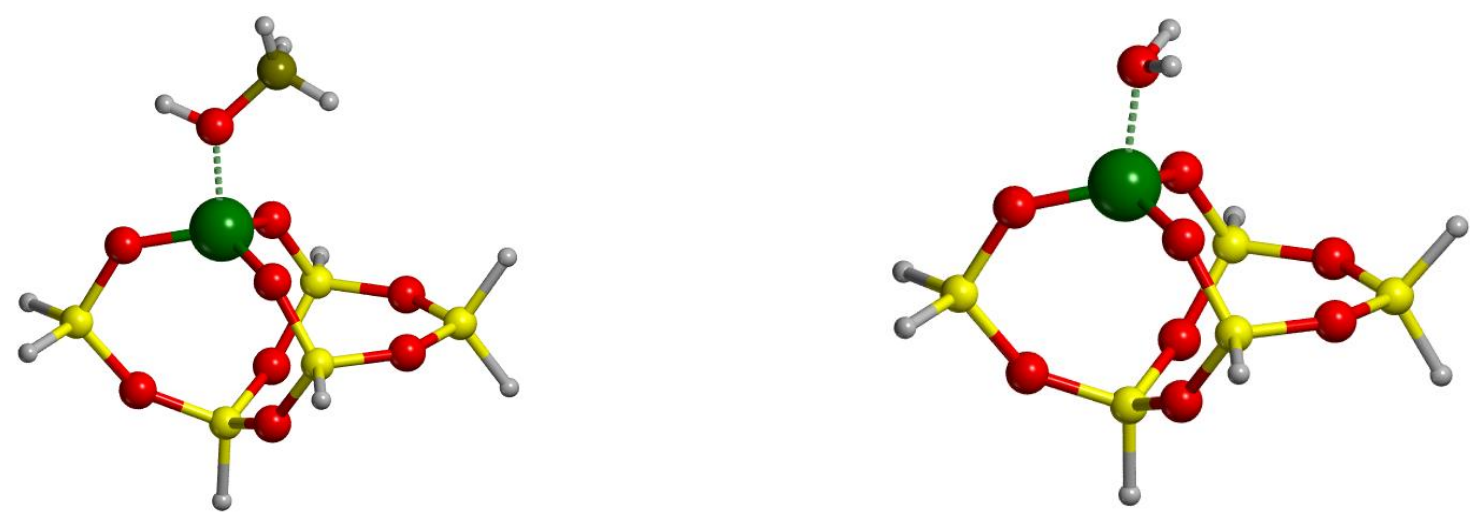

(a) $\mathrm{BE}=125 \mathrm{~kJ} / \mathrm{mol}$

(b) $\mathrm{BE}=110 \mathrm{~kJ} / \mathrm{mol}$

Fig.7

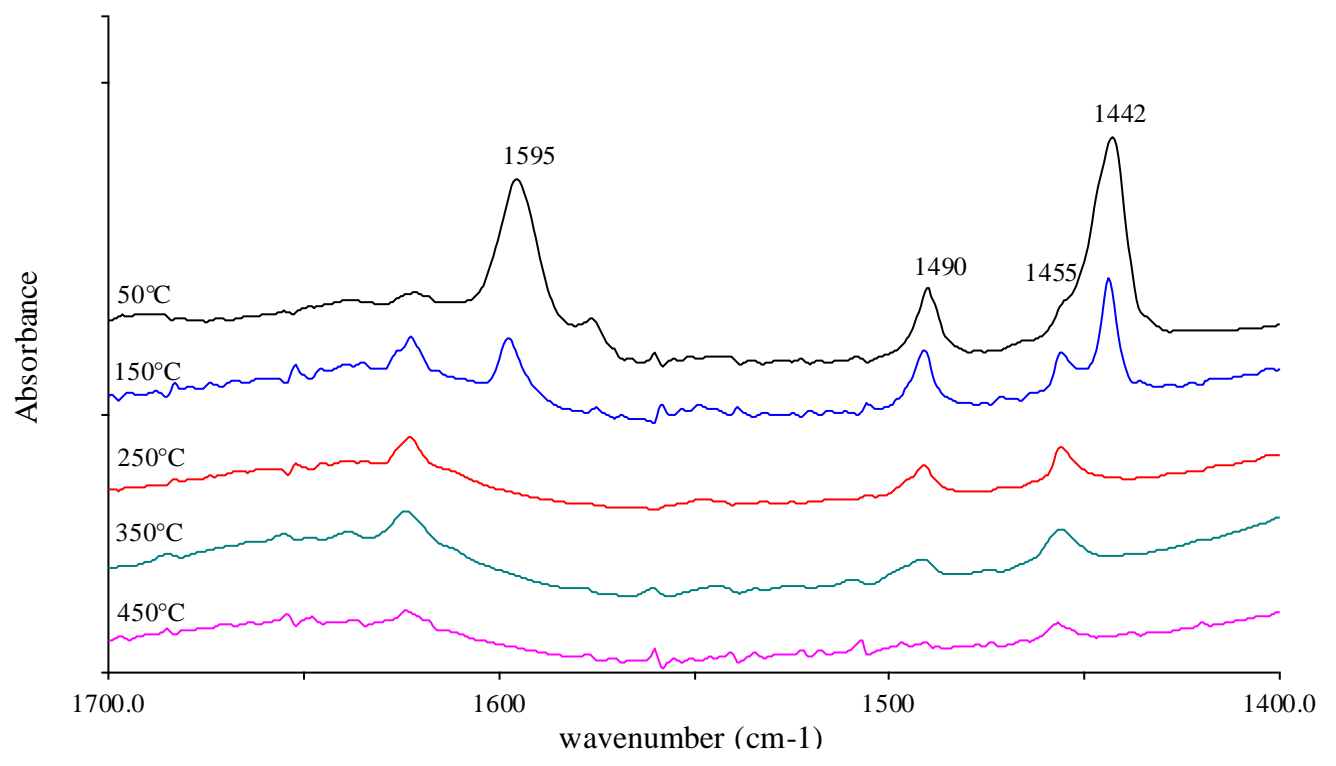

Fig.8 


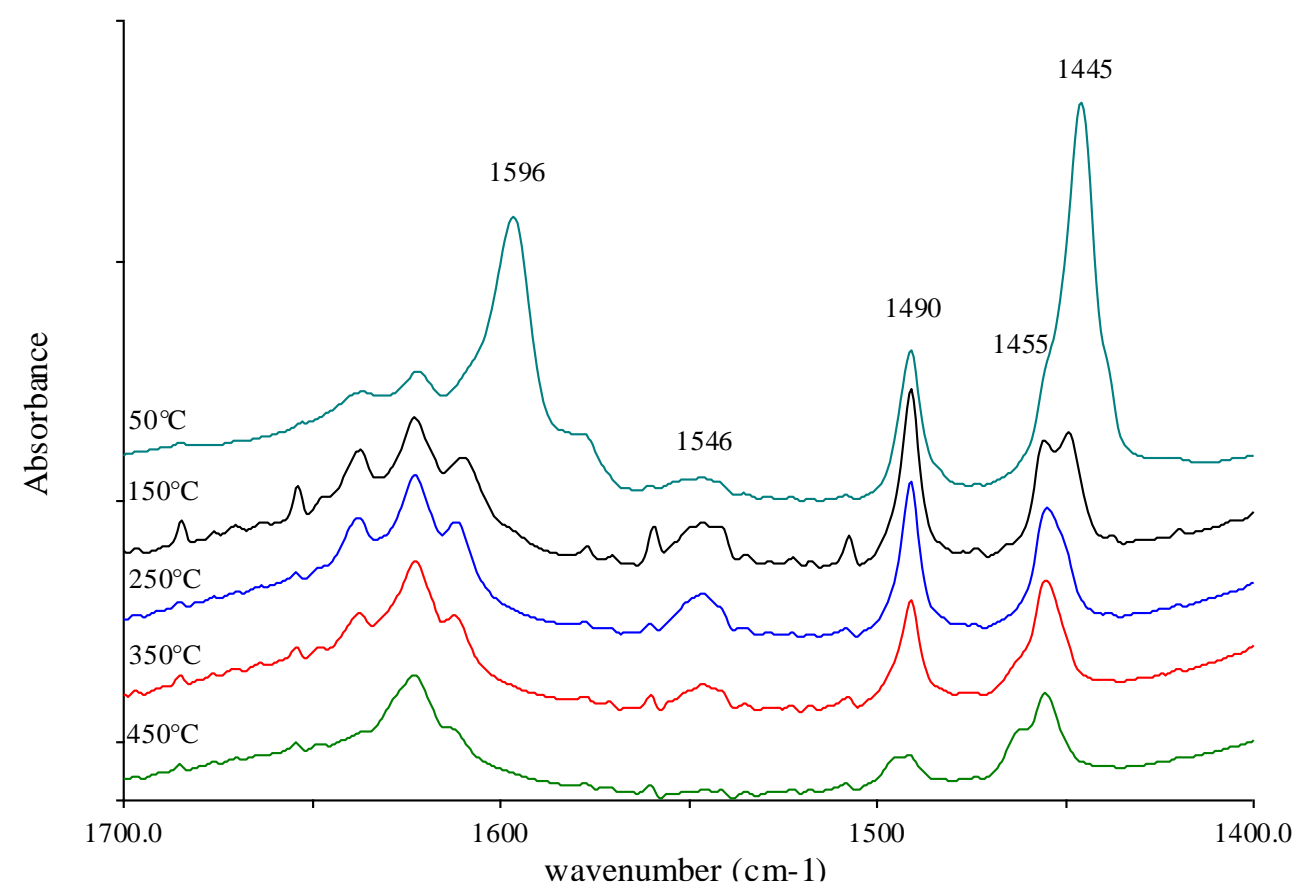

Fig.9

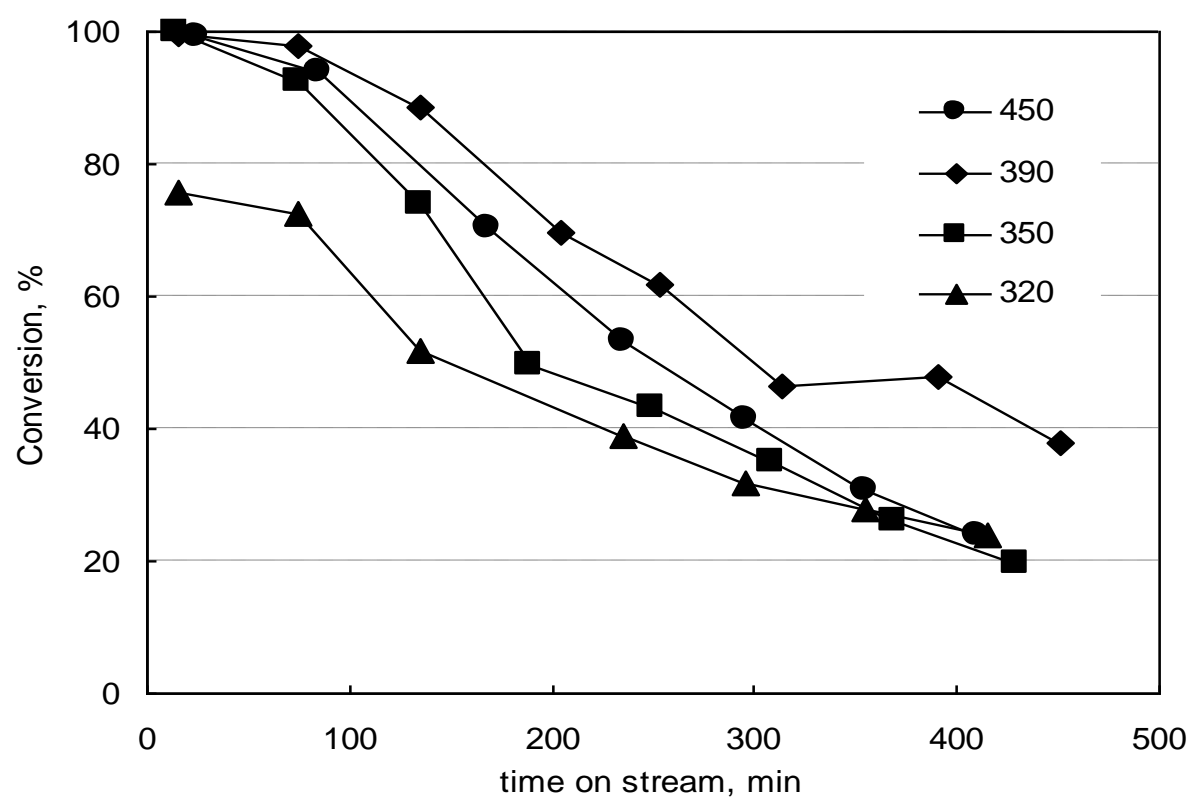

Fig.10 


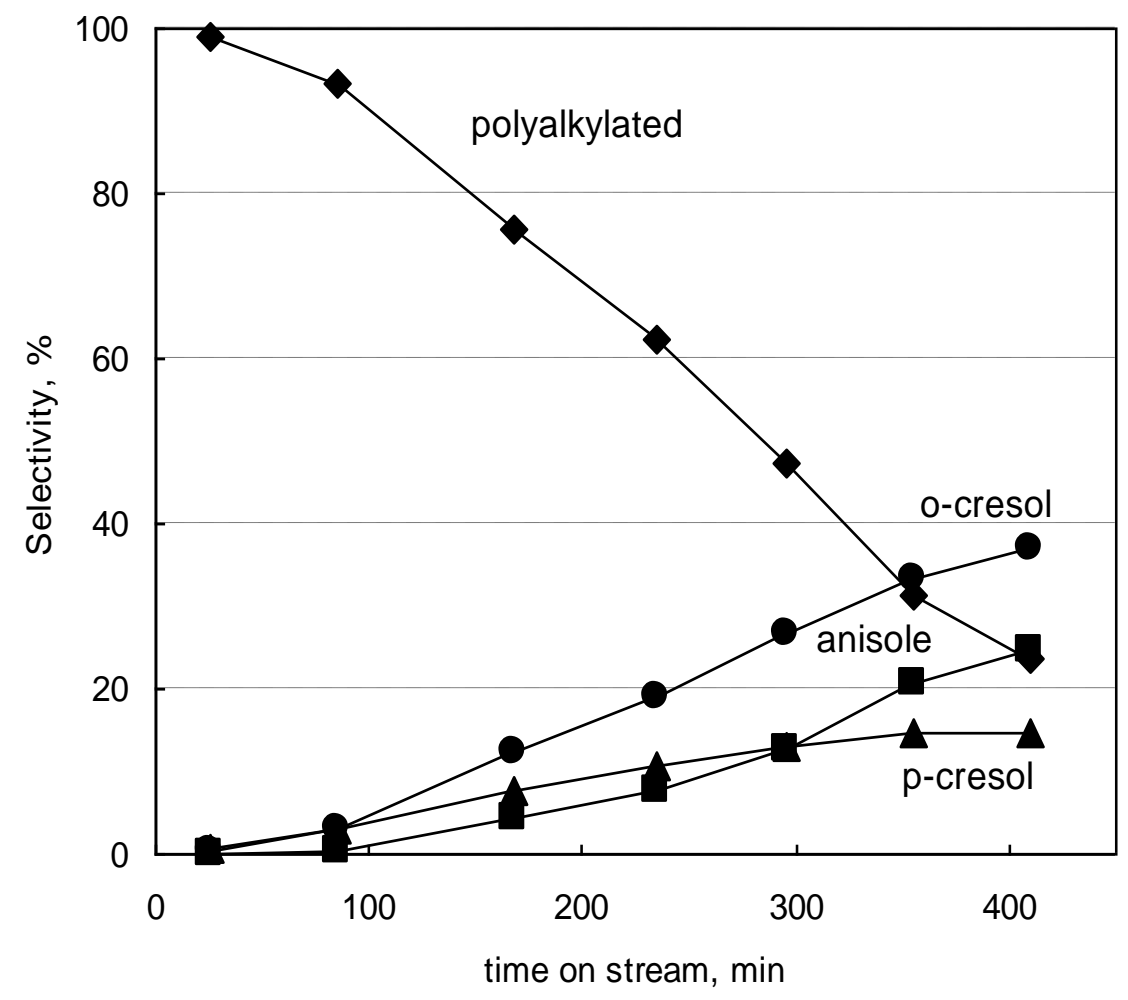

Fig.11

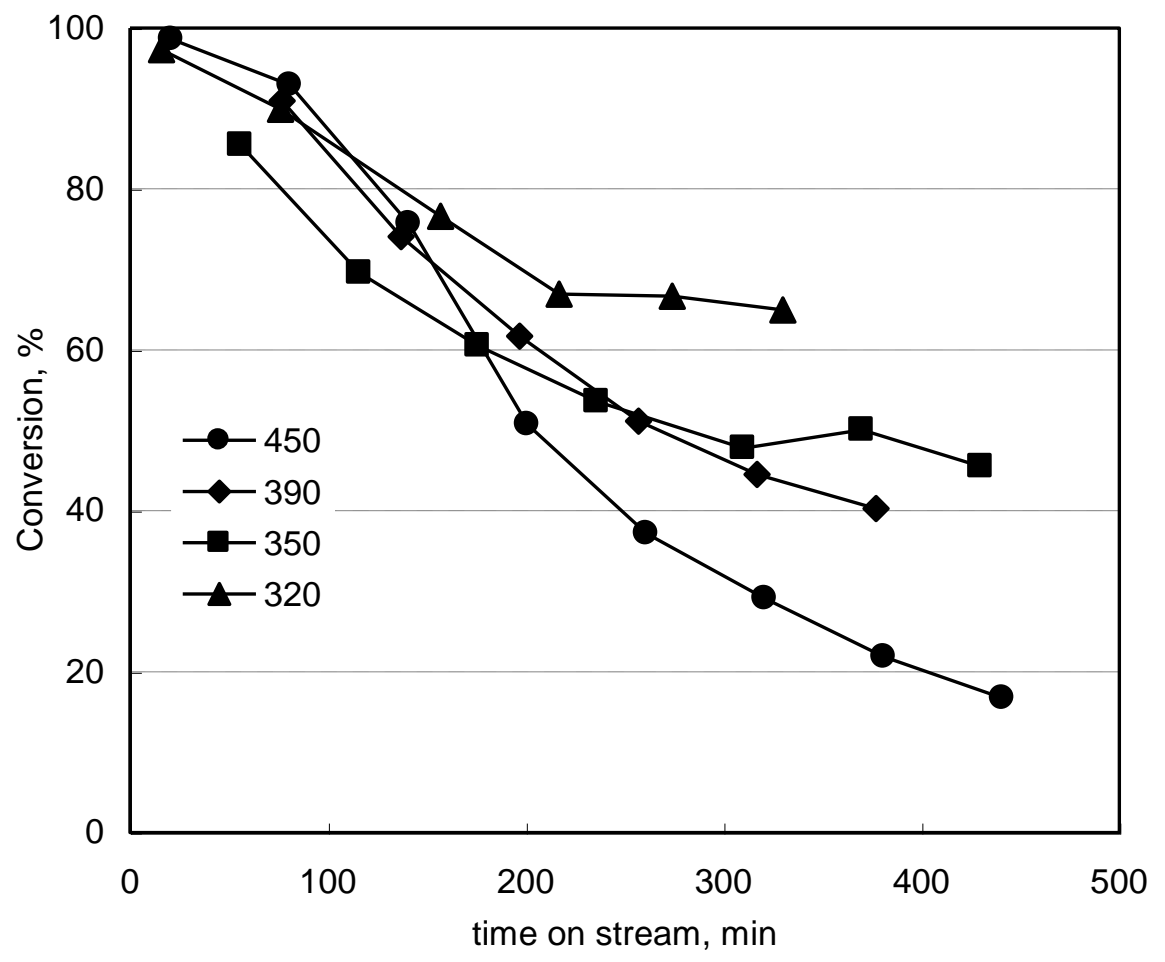

Fig.12 


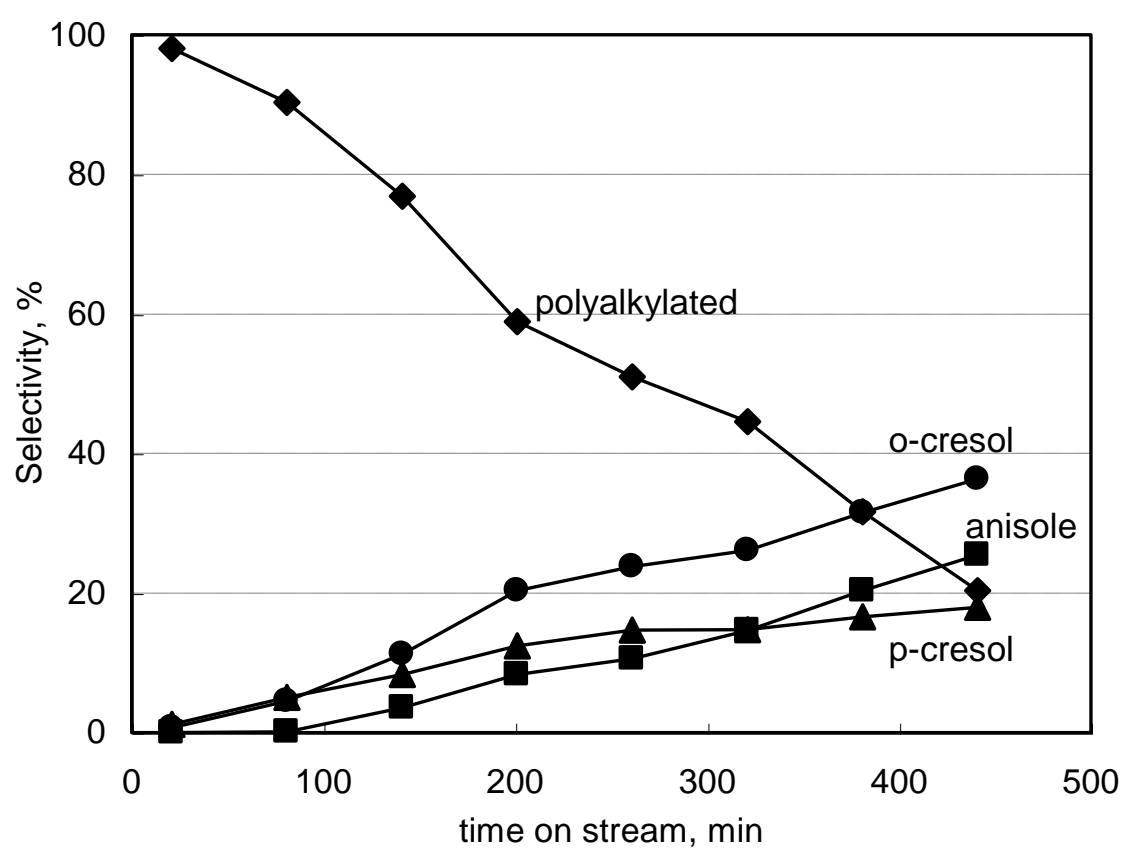

Fig.13

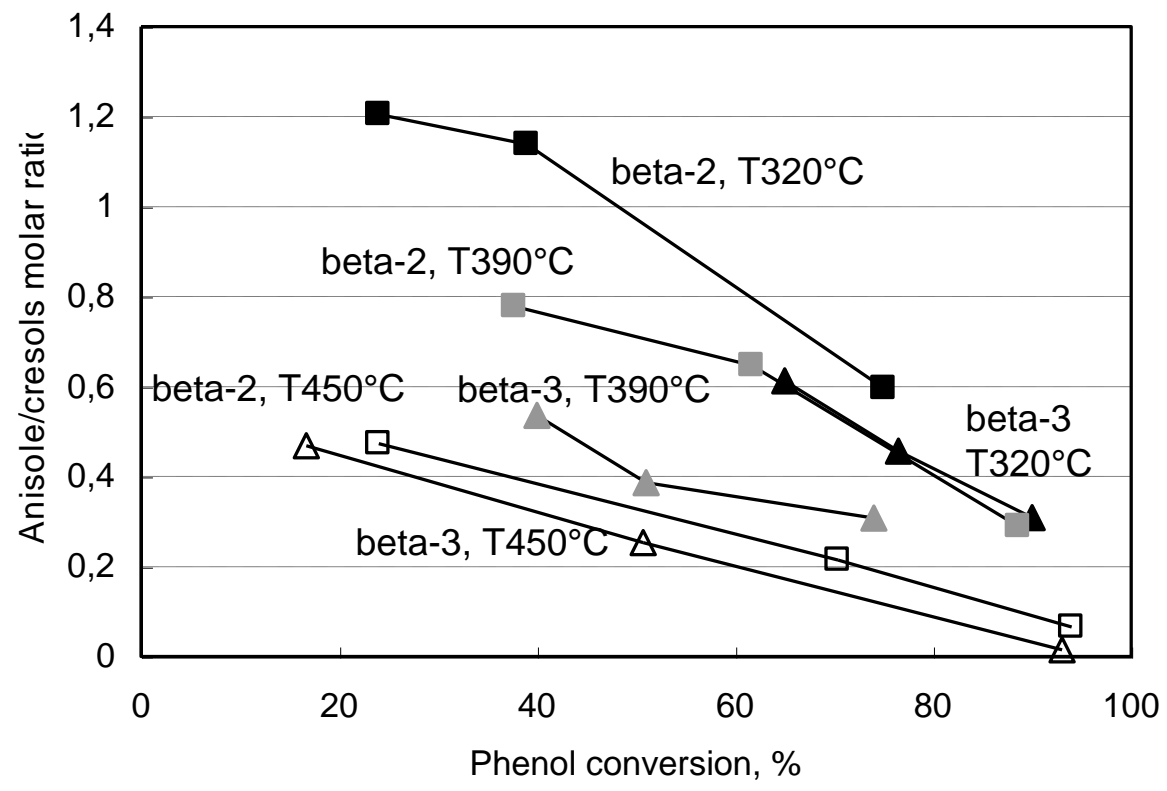

Fig. 14 


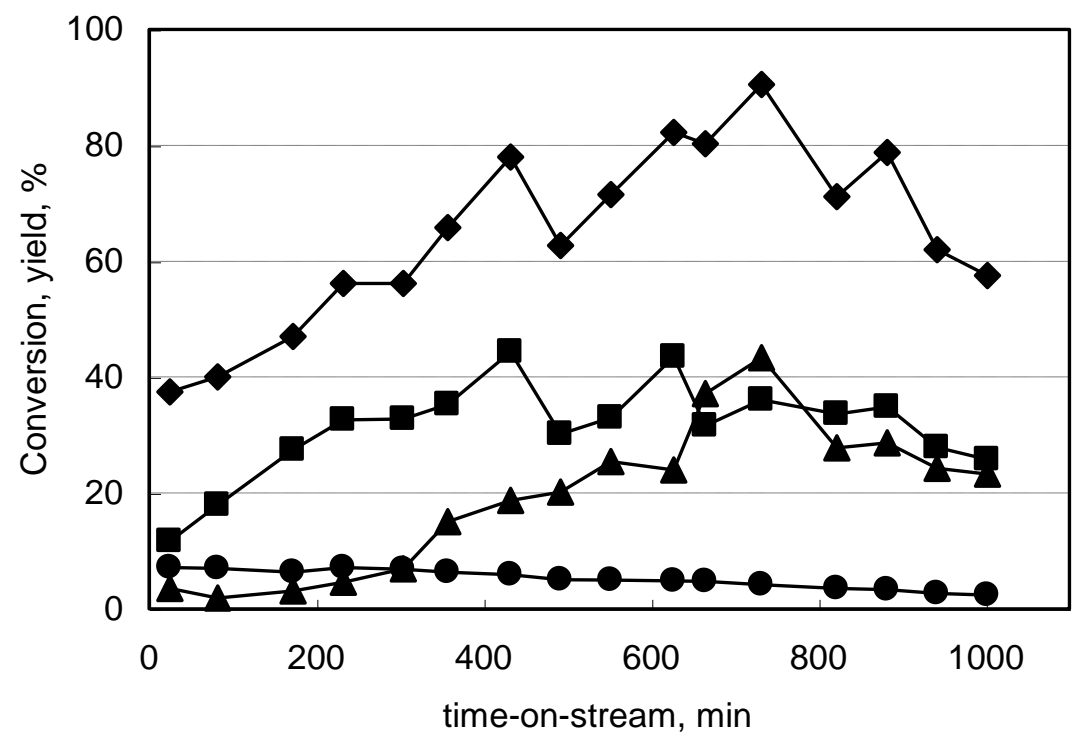

Fig.15

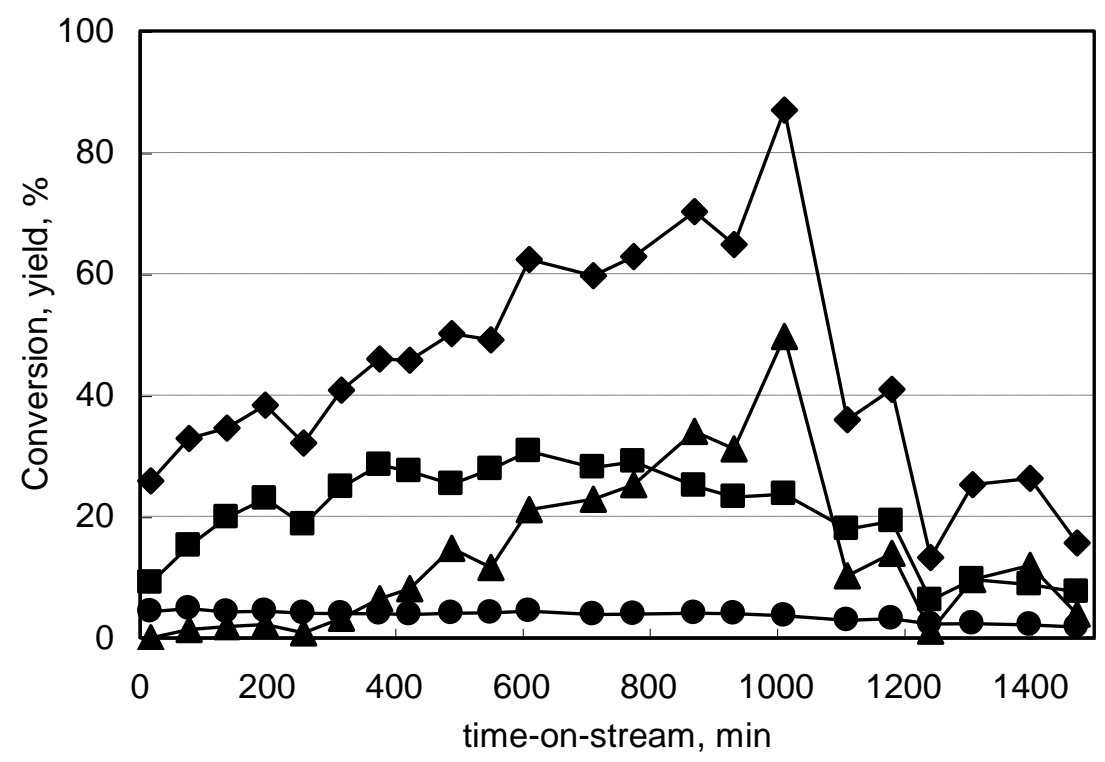

Fig.16 